\title{
Evaluation of in vitro release kinetics and mechanisms of curcumin-loaded cockle shell-derived calcium carbonate nanoparticles
}

\author{
Maryam Muhammad Mailafiya ${ }^{1,2}{ }^{\oplus}$, Kabeer Abubakar ${ }^{1,2}$, Abubakar Danmaigoro ${ }^{3}$, Samaila Musa Chiroma ${ }^{1,4}$, \\ Ezamin Bin Abdul Rahim5 ${ }^{5}$, Mohamad Aris Mohd Moklas ${ }^{1, *}$, Zuki Abu Bakar Zakaria ${ }^{6}$
}

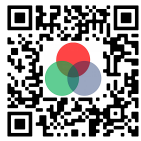

Use your smartphone to scan this QR code and download this article

${ }^{1}$ Department of Human Anatomy, Faculty of Medicine and Health Sciences, University Putra Malaysia, 43400 Serdang, Selangor Darul Ehsan, Malaysia

${ }^{2}$ Department of Human Anatomy, College of Medical Sciences, Federal University Lafia, 950101, Akunza, Lafia, Nasarawa State, Nigeria

${ }^{3}$ Department of Veterinary Anatomy, Faculty of Veterinary Medicine, Usman Danfodiyo University, 840213, Sultan Abubakar Sokoto State, Nigeria

Correspondence

Mohamad Aris Mohd Moklas

Department of Human Anatomy, Faculty of Medicine and Health Sciences,

University Putra Malaysia, 43400

Serdang, Selangor Darul Ehsan, Malaysia

Email: aris@upm.edu.my

History

- Received: Sep 08, 2019

- Accepted: Nov 10, 2019

- Published: Dec 21, 2019

DOI : 10.15419/bmrat.v6i12.580

\section{Check for updates}

\section{Copyright}

(C) Biomedpress. This is an openaccess article distributed under the terms of the Creative Commons Attribution 4.0 International license.

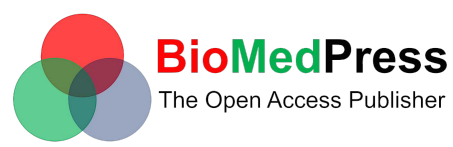

\begin{abstract}
Introduction: Curcumin has remarkable pharmacological activities but remains clinically constrained due to its poor bioavailability as a result of insolubility. This has necessitated the search for natural inorganic materials for curcumin delivery. Cockleshells are external hard materials of marine animals often treated as unwanted wastes, which are excellent sources of calcium carbonate. This study aimed to synthesize cockle shell-derived calcium carbonate (aragonite) nanoparticles ( $\left.\mathrm{CSCaCO}_{3} \mathrm{NP}\right)$ for delivery of curcumin and to evaluate its kinetic release in vitro. Methods $\mathrm{CSCaCO}_{3} \mathrm{NP}$ was synthesized and conjugated with curcumin (Cur-CSCaCO $3 \mathrm{NP}$ ) using a simple top down approach and characterized for its physicochemical properties as a potential curcumin carrier. The in vitro release profile was assessed using the dialysis bag membrane method. The release data were fitted to Korsmeyer-Peppas, Zero order, and Higuchi models to evaluate the mechanism(s) of the release pattern. Results: A spherical shaped $\mathrm{CSCaCO}_{3} \mathrm{NP}$ with a surface area of $14.48 \pm 0.1 \mathrm{~m}^{2} / \mathrm{g}$, with mean diameter size of $21.38 \pm 2.7 \mathrm{~nm}$ and zeta potential of $-18.7 \mathrm{mV}$, was synthesized and found to have high loading content and encapsulation efficiency. The FT-IR and XRD revealed fewer observable changes on the peaks after conjugation. The profile of the in vitro kinetic release demonstrated a sustained release, and which was best fitted to the Higuchi equation model. Conclusion: The results of this study showed the capacity of the synthesized $\mathrm{CSCaCO}_{3} \mathrm{NP}$ to encapsulate curcumin efficiently with a stable release in vitro. This provides insight into and rationale for the potential of $\mathrm{CSCaCO}_{3} \mathrm{NP}$ for curcumin delivery. Therefore, $\mathrm{CSCaCO}_{3} \mathrm{NP}$ holds great prospects in the preclinical framework for enhancing curcumin efficacy in oral therapeutic applications.
\end{abstract}

Key words: Aragonite, Cockleshell, Curcumin, Kinetic release, Nanoparticles, Therapeutics

\section{INTRODUCTION}

Over the last few decades, sequential encroachment of nanotechnology in the field of biomedicine has advanced the development of therapeutic agents, especially nanoparticle-based agents which have gradually shown beneficial impacts in scientific research ${ }^{1-4}$. The advanced interdisciplinary field of research has led to a forward-thinking division of sciences, traversing across many fields of research, including engineering, agricultural sciences, cosmetics, food science and technology, biology, biomedical sciences, and pharmaceutical sciences ${ }^{5}$. The rapidly burgeoning multidisciplinary field of nanomedicine has spread across sciences, with outstanding efficiency in manipulating bulk biogenic materials ranging from extremely small to more significant dimensions on nanoscales ${ }^{6}$.

Curcumin (diferuloylmethane) is a yellow non-toxic, highly potent biological active substance that is isolated from the rhizome of turmeric (Curcuma longa
L.) that belongs to the ginger family (Zingiberaceae $)^{7,8}$. It possesses numerous health benefits due to its potent medicinal values, great pharmacological effects, as well as wide safety margin; however, it has limitations too, including poor bioavailability when administered orally (due to its insolubility) and rapid degradation in alkaline $\mathrm{pH}$ environment ${ }^{7}$. It is one among the most insoluble therapeutic agents that have poor bioavailability when administered orally ${ }^{9}$. Moreover, a high percentage of curcumin is digested easily in the gastrointestinal tract (GIT) due to rapid metabolism, resulting in a high amount of curcumin being excreted, thus leaving behind only a few traces ${ }^{10}$.

Approximately $70 \%$ of all discovered drugs and medicinal plant candidates are poorly soluble. About $40 \%$ of the oral immediate-release (IR) drugs as well as many herbs are practically insoluble, as documented in the literature by previous studies ${ }^{11,12}$. 
${ }^{4}$ Department of Human Anatomy, Faculty of Basic Medical Sciences, University of Maiduguri, 600230, Maiduguri, Borno State, Nigeria

${ }^{5}$ Department of Radiology, Faculty of Medicine and Health Sciences, University Putra Malaysia, Serdang 43400, Selangor Darul Ehsan, Malaysia

${ }^{6}$ Department of Preclinical Sciences Faculty of Veterinary Medicine, University Putra Malaysia, Serdang 43400, Selangor Darul Ehsan, Malaysia
The poor oral bioavailability emanating from insoluble drugs presents some recurring challenges for drug research and development. A consistent paucity of effectiveness of orally administered drugs, resulting in poor bioavailability, is generally because of dissolution-limited absorption by the body ${ }^{12,13}$. Usually, a high dose of curcumin is required to overcome such conditions, thereby maximizing its concentration in the blood to be of equal range with the therapeutic blood concentration ${ }^{12,14}$. These challenges have led to significant setbacks of curcumin as a standard therapeutic agent ${ }^{15,16}$. However, to guard curcumin and enable it to be highly efficacious, one could theoretically protect it from direct contact with the gastrointestinal contents via direct uptake by the cells, thus boycotting fast metabolism and rapid chemical degradation ${ }^{8}$. Thus, encapsulation within delivery vehicles can enable sustained release and maximum absorption of curcumin in the upper gastrointestinal tract; this drug delivery system could be achieved and holds great prospects in oral drug administration $^{8,9,16}$.

Cockle shell is a shell of marine bivalve mollusk that is also known as Anadara granosa. It is a biogenic inorganic material that is cheap, readily available, and slow to decompose due to its strong composition properties ${ }^{17}$. It is well-documented as an excellent source of abundant pure calcium carbonate in aragonite polymorphic form. Nanocarriers are certainly the most valuable functional building blocks and the most relevant tools in nanomedicine ${ }^{18}$. The everlasting interactions between research on biogenic nanocarriers and biomedicine have led researchers in the field of nanomedicine to synthesize inorganic calcium carbonate nanoparticles from naturally abundant cockle shell material for the delivery of therapeutic agents ${ }^{19,20}$.

Calcium carbonate $\left(\mathrm{CaCO}_{3}\right)$ is one of the most versatile natural materials extracted either by mining from the earth's crust or synthesized in laboratories from seashells using different standard methods of production ${ }^{21}$. It should be emphasized that $\mathrm{CSCaCO}_{3} \mathrm{NP}$ has received much attention, considering its potential ability to enhance the therapeutic index of drugs, increase physical stability of the drugs, and minimize the drugs' side effects in the body ${ }^{22,23}$. Furthermore, $\mathrm{CSCaCO}_{3} \mathrm{NP}$ has shown promising and efficacious outcome when used for drug delivery, probably due to its surface structural porosity, high loading capacity, response to $\mathrm{pH}$ degradation, numerous functional group endings for electrostatic ion bonds, and high surface area ${ }^{22}$. The applications of this biogenic inorganic carrier were reported in some pioneering studies demonstrating successful targeted delivery of drugs for cancer therapy and chemoprevention $^{23-25}$. Indeed, its safety was demonstrated using human breast cell lines, osteoblastic cell lines, and osteogenic cell lines- for its biocompatibility $19,23,25,26$ and in animal models ${ }^{27,28}$. Hence, the synthesis and use of biogenic inorganic cockle shell-derived calcium carbonate for curcumin delivery, with the ability to boost the therapeutic efficacy of curcumin, is essential.

There are several nanocarriers currently in use for curcumin delivery, which have demonstrated enhanced bioavailability and solubility. These carriers include: silk fibroin ${ }^{29}$, chitosan $^{30}$, fibrinogen ${ }^{31}$, polymer $^{32}$, solid lipid nanoparticles ${ }^{33}$, micelles $^{8}$, and Cassava starch nanoparticles ${ }^{34}$. To the best of our knowledge, no studies have yet demonstrated the usefulness of cockle shell-derived calcium carbonate (aragonite) nanoparticles for curcumin delivery.

The present study aimed to synthesize and evaluate the in vitro kinetic release mechanisms of Cur$\mathrm{CSCaCO}_{3} \mathrm{NP}$. The development of $\mathrm{CSCaCO}_{3} \mathrm{NP}$ as a potential nanocarrier for curcumin delivery was conducted using a simple top down method. Loading of curcumin onto $\mathrm{CSCaCO}_{3} \mathrm{NP}$ was carried out using a simple precipitation method, followed by the characterization of the physicochemical properties of free curcumin, $\mathrm{CSCaCO}_{3} \mathrm{NP}$ and Cur- $\mathrm{CSCaCO}_{3} \mathrm{NP}$ using standard techniques. The in vitro kinetic release pattern of curcumin and mechanism of $\mathrm{CSCaCO}_{3} \mathrm{NP}$ were evaluated using the dialysis bag membrane method, and the release data were fitted into different equation models. The size and shape of the synthesized $\mathrm{CSCaCO}_{3} \mathrm{NP}$ were adequate for the delivery of curcumin. Cur- $\mathrm{CSCaCO}_{3} \mathrm{NP}$ demonstrated adequate prolonged, steady and substantial release, regardless of the difference in the $\mathrm{pH}$ of the environment. The surface charge and large surface area obtained for the nanoparticles promoted functional loading capacity and encapsulation efficiency, which led to a sustained release of curcumin, indicating fair stability of the nanocarrier.

\section{MATERIALS AND METHODS}

\section{Chemical and Reagents}

The cockle shells used were purchased from a local wet market in Malaysia. Curcumin and phosphate buffer saline (PBS) were obtained from Sigma Aldrich (St. Louis, MO, USA). Dodecyl dimethyl betaine (BS12) was obtained from Sigma-Aldrich (Steinheim, 
Germany); the dialysis bag membrane was obtained from Sigma Aldrich (St. Louis, MO, USA). Furthermore, ethanol was obtained from Apical Scientific Sdn, Bhd (Malaysia) and the bleaching agents from Bleach Liquor Inc. (India). All other reagents and chemicals used were of analytical grade.

\section{Preparation and Development of Micron- Size Cockle Shell Powder}

The previous method was adopted in this study for the preparation of micron-size $\mathrm{CaCO}_{3}$ nanoparticles with little modifications ${ }^{22}$. Briefly, $250 \mathrm{~g}$ of cockle shells were washed thoroughly in running tap water to get rid of dirt and stains. They were boiled in a steel container, rewashed in a liquid containing $100 \mathrm{ml}$ of water and $25 \mathrm{ml}$ of bleaching agent (Bleach Liquor) at a ratio of 3:1, and scrubbed with a hard brush to remove the remaining stains and debris from the shells. The shells were oven-dried in a Memmert UM 2500 oven (Memmert, Inc., Germany) at $50{ }^{\circ} \mathrm{C}$ for two weeks. The dried cockle shells were grounded using a rotary pulverizing blending machine (RT-08 rpm 2500, Taiwan) into fine powder particles. The fine particles were sieved using a stainless laboratory test sieve with an aperture size of $90 \mu \mathrm{m}$ followed by a smaller pore sized sieve of $75 \mu \mathrm{m}$ (Endecotts Ltd., London, England). Finally, the micron-size $\mathrm{CSCaCO}_{3}$ fine powder was stored in an oven at $50{ }^{\circ} \mathrm{C}$ for further analysis.

\section{Synthesis of $\mathrm{CaCO}_{3}$ Nanoparticles from Micron-Sized Cockle Shell Powder}

Synthesis of cockle shell $\mathrm{CaCO}_{3}$ nanoparticles was carried out using a top-down method by mechanical milling ${ }^{22}$. Briefly, $2 \mathrm{~g}$ of $75 \mu \mathrm{m}$ micron-sized cockle shell $\mathrm{CaCO}_{3}$ fine powder was mixed with $50 \mathrm{ml}$ of deionized water to make an aqueous solution in a flat bottom flask, of which $0.5 \mathrm{ml}$ of dodecyl dimethyl betaine (BS-12) was added to the solution. A magnetic stirring bar was dropped in the solution beaker to promote the stirring process, and the beaker was placed on a Systematic Multi-Hotplate Stirring machine (Systematic Multi-Hotplate Stirrers 6 Positions, Wise Stir ${ }^{\circ}$, Korea) stirring at $1000 \mathrm{rpm}$ at $27{ }^{\circ} \mathrm{C}$ for $3 \mathrm{hrs}$, after which the aqueous solution was filtered with a filter paper (Filter, Fiorina, China). Repeated rinsing of the surfactant (BS-12) from the resultant sediments was achieved by continuous rinsing with deionized water until surfactant-free nanoparticles were obtained, after which they were allowed to dry in an oven at $50{ }^{\circ} \mathrm{C}$ for 3 days. The synthesized nanoparticles were further placed and sealed with seven ceramic balls in a cylindrical iron jar that has a diameter of $8 \mathrm{~cm}$; they were then rolled on the roller mill machine for 8 days at 200 rpm. Finally, fine $\mathrm{CSCaCO}_{3} \mathrm{NP}$ were obtained, packaged in a glass bottle, and stored at $50^{\circ} \mathrm{C}$ in an oven for later use.

\section{Loading of Curcumin onto $\mathrm{CSCaCO}_{3} \mathrm{NP}$}

The loading of curcumin onto $\mathrm{CSCaCO}_{3} \mathrm{NP}$ was carried out according to past methods described in the literature with slight modifications ${ }^{6,29}$. Briefly, six formulations of Cur- $\mathrm{CSCaCO}_{3} \mathrm{NP}$ with different ratios of nanoparticles to curcumin were analyzed (Table 1). Each sample of the weighed curcumin was dissolved in $1 \mathrm{ml}$ of ethanol, followed by $5 \mathrm{ml}$ of deionized water, and then vortexed for 2 mins (3 times) with 15 secs resting intervals, after which the individual samples of curcumin solution were mixed with $\mathrm{CSCaCO}_{3} \mathrm{NP}$, respectively. The mixtures were stirred on a Systematic Multi-Hotplate Stirring machine with a magnetic bar placed in each solution to enhance the mixing process. The stirring process took place in a dark room overnight at $200 \mathrm{rpm}$. The resultant solutions were ultra-centrifuged at 20,000 rpm for $20 \mathrm{~min}$ at $4{ }^{\circ} \mathrm{C}$ (Optima XPN, Beckman Coulter instruments Inc., CA, USA), after which each solution was washed twice with $5 \mathrm{ml}$ of deionized water to remove the excess ethanol and remaining curcumin that was not encapsulated. Finally, the samples were freeze-dried and crushed into fine powder again.

\section{Curcumin Loading Capacity (LC) and Encap- sulation Efficiency (EE)}

The loading capacity (LC) and encapsulation efficiency (EE) of $\mathrm{CSCaCO}_{3} \mathrm{NP}$ on curcumin were determined by substituting the difference between the total amount used to prepare the nanoparticles and the amount of compound present in the aqueous phase after ultra-centrifugation per weight of the $\mathrm{CaCO}_{3} \mathrm{NP}$. Thus, the loading capacity was calculated by dividing the weight of the total encapsulated drug in nanoparticles by the total weight of the nanoparticles, which is expressed as percentage; it is the total amount of drug delivered per amount encapsulated ${ }^{22}$. Encapsulation efficiency is the total amount of drug entrapped or loaded per unit of the initial weight of the nanoparticles, which is expressed as percentage. It gives the exact amount of the drug entrapped by the nanocarrier after loading ${ }^{25}$. The weight of the total drug entrapped was determined by subtracting the weight of the total drug fed from the weight of the nonencapsulated drug or unfed drug (total weight of the drug fed minus total weight of the unfed drug). The amount of the free curcumin in the supernatant was 


\begin{tabular}{llll}
\hline \multicolumn{4}{l}{ Table 1: Formulations of Cur- $\mathrm{CSCaCO}_{3}$ NP with different ratios of nanoparticles to curcumin } \\
\hline $\mathrm{CODE}$ & $\mathrm{CSCaCO}_{3} \mathrm{NP}(\mathrm{mg})$ & CURCUMIN $(\mathrm{mg})$ & RATIO \\
\hline 1 & 20 & 30 & $2: 3$ \\
2 & 20 & 20 & $1: 1$ \\
3 & 20 & 10 & $2: 1$ \\
4 & 10 & 30 & $1: 3$ \\
5 & 10 & 20 & $1: 2$ \\
6 & 10 & 10 & $1: 1$ \\
\hline
\end{tabular}

determined by measuring the absorbance at a maximum wavelength of $430 \mathrm{~nm}$ via spectrophotometry (PerkinElmer Lambda 35 Boston, MA, USA). Data were obtained by measuring the samples in triplicates and the values averaged to obtain the mean. The loading capacity/content (LC) and encapsulation efficiency (EE) were calculated by the following equations (1) and (2) below, respectively:

Loading Content $(\mathrm{LC} \%)=\frac{W_{t}-W_{f}}{W_{N p}} \times 100 \ldots$ (1)

Encapsulation Efficiency (EE \%) $=\frac{W_{t}-W_{f}}{W_{t}} x 100 \ldots$ (2)

Note: $\mathrm{W}_{t}=$ Total weight of drug fed, $\mathrm{W}_{f}=$ Total weight of the non-encapsulated drug (free drug), $\mathrm{W}_{N P}=$ Weight of the nanoparticles.

\section{Characterization of $\mathrm{CSCaCO}_{3} \mathrm{NP}$ and Cur- $\mathrm{CSCaCO}_{3} \mathrm{NP}$}

Physicochemical properties of $\mathrm{CSCaCO}_{3} \mathrm{NP}$ and Cur$\mathrm{CSCaCO}_{3} \mathrm{NP}$ were examined by Transmission electron microscope (TEM), Field electron-surface electron microscope (FE-SEM), Fourier transform infrared rays (FT-IR), X-ray diffractometer (XRD), Zeta sizer, and Brunauer-Emmett-teller (BET) for determination of size and shape, surface morphology, functional groups, purity and crystallinity, surface charge and polydispersity index (PDI), and pore size and surface area, respectively.

\section{Determination of Nanosize and Shape using TEM}

The size and shape of $\mathrm{CSCaCO}_{3} \mathrm{NP}$ and Cur$\mathrm{CSCaCO}_{3} \mathrm{NP}$ were determined using TEM (Hitachi H-7100, Japan). Both separate samples (0.1 mg each) were suspended dropwise in $1 \mathrm{ml}$ of acetone ( $45 \%$ alcohol) plus $2 \mathrm{ml}$ of deionized water for $30 \mathrm{~min}$ ultrasonication (Power Sonic 505, South Korea). The supernatant was added in dropwise fashion to 200-mesh carbon coated copper grid (Sigma-Aldrich, USA), and then the excess liquid was blotted out using filter paper and dropped onto Whatman paper (Fisher Scientific, Malaysia) in a petri dish, after which it was air dried at room temperature and preserved in a desiccator for $48 \mathrm{~h}$ before viewing. The TEM measurements were carried out at $150 \mathrm{k}^{22,35}$.

\section{Determination of Surface Morphology using FE-SEM}

Cross-sectional surface morphology of $\mathrm{CSCaCO}_{3} \mathrm{NP}$ and $\mathrm{Cur}-\mathrm{CSCaCO}_{3} \mathrm{NP}$ were determined using $\mathrm{FE}$ SEM (JOEL 7600F, JEOL, Munich, Germany). The thin layer of gold palladium was coated with samples $(5 \times 5 \mathrm{~mm})$, placed on adhesive stubs, and viewed. The working voltage of FE-SEM was set at $5.0 \mathrm{kV}$.

\section{Chemical Spectroscopy using a Fourier Transform Infrared Rays (FT-IR)}

Potential interactions between the chemical constituents to depict the functional groups of $\mathrm{CSCaCO}_{3} \mathrm{NP}$, Cur-CSCaCO${ }_{3} \mathrm{NP}$, and free curcumin were analyzed by FT-IR (Model 100 series, Perkin Elmer, USA) at a range of $4000 \mathrm{~cm}^{-1}$ to $400 \mathrm{~cm}^{-1}$, with a resolution of $1 \mathrm{~cm}^{-1}$ and average scan of 64 times.

\section{XRD-Powder Diffraction Determination}

The purity and crystallinity of $\mathrm{CSCaCO}_{3} \mathrm{NP}$, Cur$\mathrm{CSCaCO}_{3} \mathrm{NP}$, and free curcumin were assessed using an X-ray powder diffractometer (Shimadzu XRD-600 powder diffractometer, Japan) equipped with $\mathrm{CuK}$ $(\mathrm{A}=1.540562 \mathrm{~nm})$ at $30.0 \mathrm{kV}$ and $30 \mathrm{~mA}$. The phase of each sample was determined based on diffraction angles of $5.0^{\circ}-60^{\circ}$ continuously at room temperature. The radiation source was scanned at a rate of $2.00(\% / \mathrm{min})$.

\section{Particle Size and Zeta Potential Analysis}

The mean size diameter, PDI, and surface charge (zeta potential) of $\mathrm{CSCaCO}_{3} \mathrm{NP}$ and $\mathrm{Cur}-\mathrm{CSCaCO}_{3} \mathrm{NP}$ 
were measured with a Zeta-sizer Nano ZS, Malvern instrument (Malvern Version 7.02, Malvern Instruments Ltd., UK). About $0.1 \mathrm{mg}$ of $\mathrm{CSCaCO}_{3} \mathrm{NP}$ and Cur- $\mathrm{CSCaCO}_{3} \mathrm{NP}$ were dissolved separately in $12 \mathrm{ml}$ of $\mathrm{pH} 7.4$ solution (normal physiological condition) and ultra-sonicated for approximately 30 minutes at room temperature before the analysis. The supernatant was loaded into a disposable cuvette using a syringe attached with a $0.2 \mu \mathrm{l}$ filter. The analysis was performed at $25^{\circ} \mathrm{C}$ with dynamic light scattering detected at angle $90^{\circ}$. The uniformity of the size distribution was determined from the PDI. All the measurements were made at a constant solution in triplicates $(n=3)$, and the average values were taken to determine the zeta potential as described earlier ${ }^{25,36}$.

\section{Pore Size and Surface Area Determination using BET}

The surface area to volume ratio analysis was done in accordance with that of Danmaigoro et al. ${ }^{22}$ with slight modifications. The pore size and specific surface area of the $\mathrm{CSCaCO}_{3} \mathrm{NP}$ were determined using a 3-flex surface characterization analyzer (BrunauerEmmett-teller Micrometrics, Instrument Corporation, version 1.02, USA) which was incorporated with nitrogen gas adsorption/desorption isotherm at $77.219 \mathrm{~K}$ using a total sample weight of $0.2065 \mathrm{~g}$. Initially, the sample was outgassed at $90{ }^{\circ} \mathrm{C}$ for $60 \mathrm{~min}$ using the equilibrium interval of $10 \mathrm{~s}$ and a sample density of $1.0 \mathrm{~g} / \mathrm{cm}^{3}$, based on the adsorption and desorption isotherm at a relative pressure $(P / P 0)$ range of 0.009 to 0.13 . The data obtained were analyzed using the BET and Barrett-Joyner-Halenda (BJH) models to determine the $\mathrm{BJH}$ mean pore size distribution, isotherm type, total volume of pore size, and BETspecific surface area.

\section{In Vitro Kinetic Release of Curcumin from $\mathrm{CSCaCO}_{3} \mathrm{NP}$}

The in vitro release of curcumin from $\mathrm{CSCaCO}_{3} \mathrm{NP}$ was determined in simulated gastric $\mathrm{pH} 1.2$ (high acidic medium), reasonable physiological condition ( $\mathrm{pH}$ 7.4), as well as $\mathrm{pH} 4.8$ (less acidic medium) simulating the blood, esophagus, intestine and cell microenvironment at ambient temperature (Supplementary). The process was performed using a dialysis bag membrane method according to procedures previously described in the literature with slight modifications ${ }^{24,37}$. In brief, $10 \mathrm{mg}$ of three separate samples of Cur-CSCaCO${ }_{3} \mathrm{NP}$ in $1 \mathrm{ml}$ of deionized water and $10 \mathrm{mg}$ of free curcumin in $1 \mathrm{ml}(100 \mu \mathrm{l}$ of ethanol and $900 \mu \mathrm{l}$ of deionized water) were put in a dialysis bags which were suspended in a glass jar containing $100 \mathrm{ml}$ of each previously mentioned respective $\mathrm{pH}$ solutions. The free curcumin solution was suspended separately in simulated gastric $\mathrm{pH} 1.2$ as blank control to serve as a comparison with Cur$\mathrm{CSCaCO}_{3} \mathrm{NP}$. Afterwards, a magnetic stirring bar was placed in each of the four solutions and placed on a digital magnetic stirring machine at $100 \mathrm{rpm}$. This was carried out at $37^{\circ} \mathrm{C}$ with slow constant stirring. At regular time intervals $(0,0.5,1,4,6,8,12,24,48$, $72,96,120,144$ and $168 \mathrm{hrs}), 1000 \mu \mathrm{l}$ of each solution was pipetted into 96-well plates for absorbance measurements and were replaced with equivalent volumes of the resultant fresh $\mathrm{pH}$ solutions to keep the volume constant. Drug release concentrations were determined at specific intervals by measuring the absorbance at $430 \mathrm{~nm}$ using a UV-vis spectrophotometer (PerkinElmer Lambda 35, Boston, MA, USA). The calculations were done according to the standard curve of concentration gradients of free curcumin at the range of $0.5-2 \mathrm{mg} / \mathrm{ml}$ (Supplementary). The experiment was repeated in triplicates with the concentration of curcumin released in the various simulated media expressed as a percentage of the initial sample (Equation (3)). The release kinetics of Cur$\mathrm{CSCaCO}_{3} \mathrm{NP}$ were studied using Korsmeyer-Peppas, Higuchi, and zero order equation models; the data generated were plotted using regression analysis ${ }^{38,39}$.

Curcumin released $(\%)=$

$\frac{\text { Concentration of curcumin released }}{\text { Initial total curcumin concentration }} \times 100$

\section{Data analysis}

The data obtained were expressed as the mean \pm standard error of the mean (SEM). $P$-value $<0.05$ was considered significant where applicable. Twoway ANOVA and linear regression analysis were employed. The data analysis was conducted using GraphPad Prism (GraphPad Software, Inc., version 6.01, USA), OriginPro software version 9.0 with 32bit ink (OriginLab Corporation, USA), and SPSS version 25 (IBM, USA).

\section{RESULTS}

\section{Encapsulation Efficiency (EE) and Loading Capacity (LC)}

Curcumin was successfully loaded onto $\mathrm{CSCaCO}_{3} \mathrm{NP}$ with variations on the loading capacity and highefficient encapsulation. A clear summary of the 
loading capacity and encapsulation efficiency of $\mathrm{CSCaCO}_{3} \mathrm{NP}$ to curcumin is shown in Table 2, with differences exhibited by $\mathrm{CSCaCO}_{3} \mathrm{NP}$ on the loading capacity and encapsulation efficiency. Good encapsulation efficiency and loading capacity were observed in all the theoretical ratios. However, equal ratios of $\mathrm{CSCaCO}_{3} \mathrm{NP}$ to curcumin (Code 2 and 6) provided high LC $\%$ and $\mathrm{EE} \%$. Code 4 with a $1: 3$ ratio of $\mathrm{CSCaCO}_{3} \mathrm{NP}$ to curcumin (10 $\mathrm{mg}$ of $\mathrm{CSCaCO}_{3} \mathrm{NP}$ and $30 \mathrm{mg}$ of curcumin) is shown in Table 2, and was chosen for subsequent analysis in this study. The EE was affected by the amount of curcumin with regards to the different ratios of the curcumin to nanoparticles used; hence, the total percentage entrapments were seen decreasing as the amounts of curcumin increased. Cur-CSCaCO${ }_{3} \mathrm{NP}$ was seen to be soluble after loading with the nanoparticles (Figure 1), although the yellow coloration was still visible.

\section{TEM}

Spherical shapes with porosity were observed on TEM (Figure 2a) with a mean diameter of $21.38 \pm 2.7$ $\mathrm{nm}$, as seen in Figure 2 b. Additionally, sphericalshaped nanoparticles were observed after loading (Cur- $\left.\mathrm{CSCaCO}_{3} \mathrm{NP}\right)$, as seen in Figure 3a, with a mean diameter of $45.32 \pm 5.05 \mathrm{~nm}$ (Figure $3 \mathbf{b}$ ). The Gaussian distribution of $\mathrm{CSCaCO}_{3} \mathrm{NP}$ and Cur$\mathrm{CSCaCO}_{3} \mathrm{NP}$ revealed a uniform distribution of the nanoparticles (Table 3). Additionally, the notable rough, porous nature of $\mathrm{CSCaCO}_{3} \mathrm{NP}$ with some agglomeration was observed.

\section{FE-SEM}

The cross-sectional view of the surface morphology of the synthesised $\mathrm{CSCaCO}_{3} \mathrm{NP}$ and $\mathrm{Cur}-\mathrm{CSCaCO}_{3} \mathrm{NP}$ revealed numerous unidimensional spherical-shaped nanoparticles that were fairly uniform in size and shape with rough surfaces, as shown in Figure $4 \mathbf{a}$ and Figure 4 b, respectively.

\section{Zeta Size, PDI and Charge Potential}

The zeta size of $\mathrm{CSCaCO}_{3} \mathrm{NP}$ revealed an average diameter of $50.09 \pm 1.04 \mathrm{~nm}$ (range $48.44-55.00 \mathrm{~nm}$ ) with a PDI of 0.17 and a low negative charge potential of $-18.7 \mathrm{mV}$. An increase in size, PDI, and surface charge were seen in Cur-CSCaCO${ }_{3} \mathrm{NP}$, which were $140.06 \pm 1.01 \mathrm{~nm}$ (range $137.2-144.1 \mathrm{~nm}$ ), 0.25, and -29.4 mV, respectively, as shown in Table 4and Figures 5 and 6.

\section{FT-IR}

The absorption peak spectra demonstrated the characteristic bands of $\mathrm{CSCaCO}_{3} \mathrm{NP}$, Cur- $\mathrm{CSCaCO}_{3} \mathrm{NP}$, and free curcumin from the FT-IR spectroscopy. The spectral absorption peaks of $\mathrm{CSCaCO}_{3} \mathrm{NP}$ were seen at $1786.08 \mathrm{~cm}^{-1}, 1446.61 \mathrm{~cm}^{-1}, 1082.07 \mathrm{~cm}^{-1}$, $854.47 \mathrm{~cm}^{-1}, 713.66 \mathrm{~cm}^{-1}$, and $462.92 \mathrm{~cm}^{-1}$, respectively, indicating the presence of $\mathrm{CO}_{3}{ }^{2-}$ carbonate ion on both $\mathrm{CSCaCO}_{3} \mathrm{NP}$ and $\mathrm{Cur}-\mathrm{CSCaCO}_{3} \mathrm{NP}$. The strong peaks of the three products showed similar wavelengths. Thus, the purity of the nanocarrier had not been altered by the preparation method. This confirmed successful loading of the curcumin and strong conjugation between the two compounds (Figure 7).

\section{XRD}

Crystallinity and purity nature of $\mathrm{CSCaCO}_{3} \mathrm{NP}$, Cur$\mathrm{CSCaCO}_{3} \mathrm{NP}$, and free curcumin were analyzed using XRD, which is a robust analytical tool used for assessing the purity nature and crystalline phases of sample particles. The similarities in the absorption peaks of $\mathrm{CSCaCO}_{3} \mathrm{NP}$ and $\mathrm{Cur}-\mathrm{CSCaCO}_{3} \mathrm{NP}$ at 2 thetas of $26.17^{\circ}, 28.22^{\circ}, 33.5^{\circ}$, and $45.81^{\circ}$ demonstrated the unchanged nature of the crystalline phase of $\mathrm{CSCaCO}_{3} \mathrm{NP}$ after loading with curcumin. The free curcumin demonstrated some sharp peaks at a diffraction angle of $8^{\circ}-28.92^{\circ}$ indicating a high crystalline nature (Figure 8).

\section{Brunauer-Emmett-Teller isotherm (BET)}

The synthesized $\mathrm{CSCaCO}_{3} \mathrm{NP}$ revealed an adsorption/desorption isotherm graph of type III mesoporous with a hysteresis loop showing the presence of multiple layers, with a sharp curve at a relative pressure of 0.009 to 0.13 (Figure 9). The $\mathrm{BJH}$ mean pore size diameter and BET specific surface area were 3.35 $\mathrm{nm}$ and $14.4806 \pm 0.110 \mathrm{~m}^{2} / \mathrm{g}$, respectively (Table 5).

\section{In Vitro Release Profile Studies}

The kinetic release profile of curcumin from $\mathrm{CSCaCO}_{3} \mathrm{NP}$ is demonstrated in Figure 10. Free curcumin was used as a positive control in the kinetic assay studies. Cur- $\mathrm{CSCaCO}_{3} \mathrm{NP}$ demonstrated a slow, sustained kinetic release pattern of curcumin from the core shell of $\mathrm{CSCaCO}_{3} \mathrm{NP}$, as compared to the release pattern of free curcumin from the dialysis bag. At the first phase, there was an initial slow release phase of curcumin from the core of $\mathrm{CSCaCO}_{3} \mathrm{NP}$ in pH 4.8 (2\%), pH 1.2 (3\%) and pH 7.4 (5\%), when compared to the rapid release phase of free curcumin from the membrane bag in pH 1.2 (20\%). However, a steady increasing release phase was observed for Cur-CSCaCO 3 NP in all the $\mathrm{pH}$ environments with sudden outburst release patterns amounting to the following percentages: $\mathrm{pH} 4.8$ (30\%), $\mathrm{pH} 1.2$ 


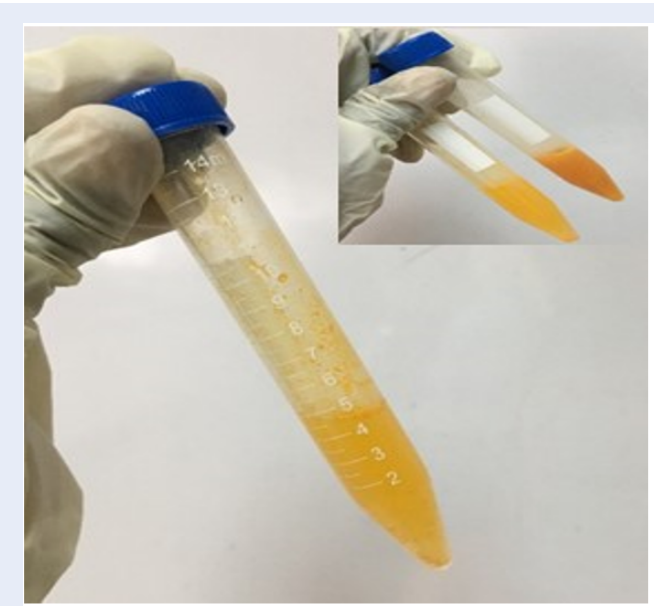

(a)

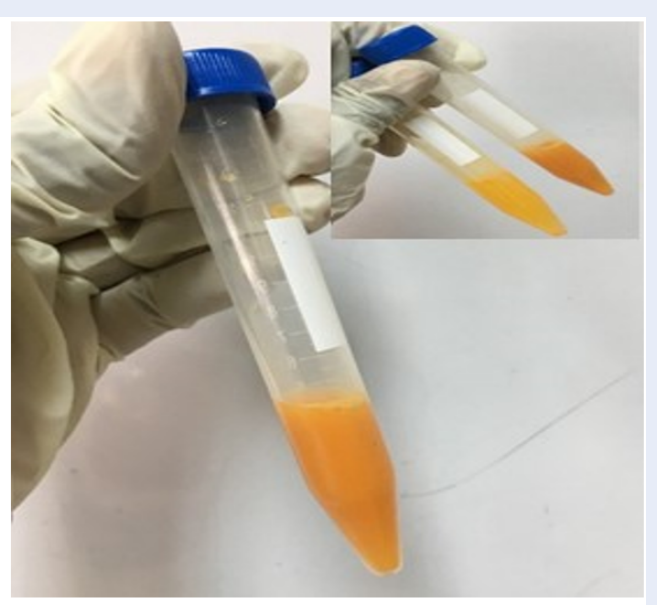

(b)

Figure 1: Effect of $\mathrm{CSCaCO}_{3} \mathrm{NP}$ on the solubility nature of curcumin in aqueous solution: (a) before loading with $\mathrm{CSCaCO}_{3} \mathrm{NP}$, or (b) after loading with $\mathrm{CSCaCO}_{3} \mathrm{NP}$.

Table 2: Effect of the weight of curcumin on $\mathrm{CSCaCO}_{3} \mathrm{NP}$ on the loading capacity and encapsulation efficiency

\begin{tabular}{lllllll}
\hline CODE & $\begin{array}{l}\mathrm{CSCaCO}_{3} \mathrm{NP} \\
(\mathrm{mg})\end{array}$ & $\begin{array}{l}\text { CURCUMIN } \\
(\mathrm{mg})\end{array}$ & $\begin{array}{l}\text { DRUG FED } \\
(\mathrm{mg})\end{array}$ & LC $\%$ & EE \% & RATIO \\
\hline 1 & 20 & 30 & 17.90 & 89.49 & 59.66 & $2: 3$ \\
2 & 20 & 20 & 12.60 & 62.99 & 62.99 & $1: 1$ \\
3 & 20 & 10 & 9.35 & 46.76 & 93.52 & $2: 1$ \\
4 & 10 & 30 & 9.76 & 97.58 & 32.53 & $1: 3$ \\
5 & 10 & 20 & 7.20 & 71.97 & 35.98 & $1: 2$ \\
6 & 10 & 10 & 9.90 & 99.03 & 99.03 & $1: 1$ \\
\hline
\end{tabular}

Table 3: The mean distribution of $\mathrm{CSCaCO}_{3} \mathrm{NP}$ and $\mathrm{Cur}-\mathrm{CSCaCO}_{3} \mathrm{NP}$

\begin{tabular}{cccc}
\hline Nanoparticles & $\begin{array}{c}\text { Diameter Size } \\
\text { Mean } \pm \text { SEM } \\
(\mathrm{nm})\end{array}$ & $\begin{array}{c}\text { Min. Value } \\
(\mathrm{nm})\end{array}$ & $\begin{array}{c}\text { Max. Value } \\
(\mathrm{nm})\end{array}$ \\
\hline $\mathrm{CSCaCO} \mathrm{NP}$ & $21.38 \pm 3.7$ & 16 & 26.20 \\
$\mathrm{Cur}-\mathrm{CSCaCO}_{3} \mathrm{NP}$ & $45.36 \pm 5.05$ & 35 & 55.00 \\
\hline
\end{tabular}

Table 4: The average size, PDI and charge potential of $\mathrm{CSCaCO}_{3} \mathrm{NP}$ and Cur-CSCaCO ${ }_{3} \mathrm{NP}$

\begin{tabular}{cccc}
\hline Nanoparticle & $\begin{array}{c}\text { Zeta size } \\
(\mathrm{nm})\end{array}$ & PDI & $\begin{array}{c}\text { Zeta Potential } \\
(\mathrm{mV})\end{array}$ \\
\hline $\mathrm{CSCaCO}_{3} \mathrm{NP}$ & $50.09 \pm 1.04$ & 0.17 & -18.7 \\
$\mathrm{Cur}^{-\mathrm{CSCaCO}_{3} \mathrm{NP}}$ & $140.06 \pm 1.01$ & 0.25 & -29.4 \\
\hline
\end{tabular}



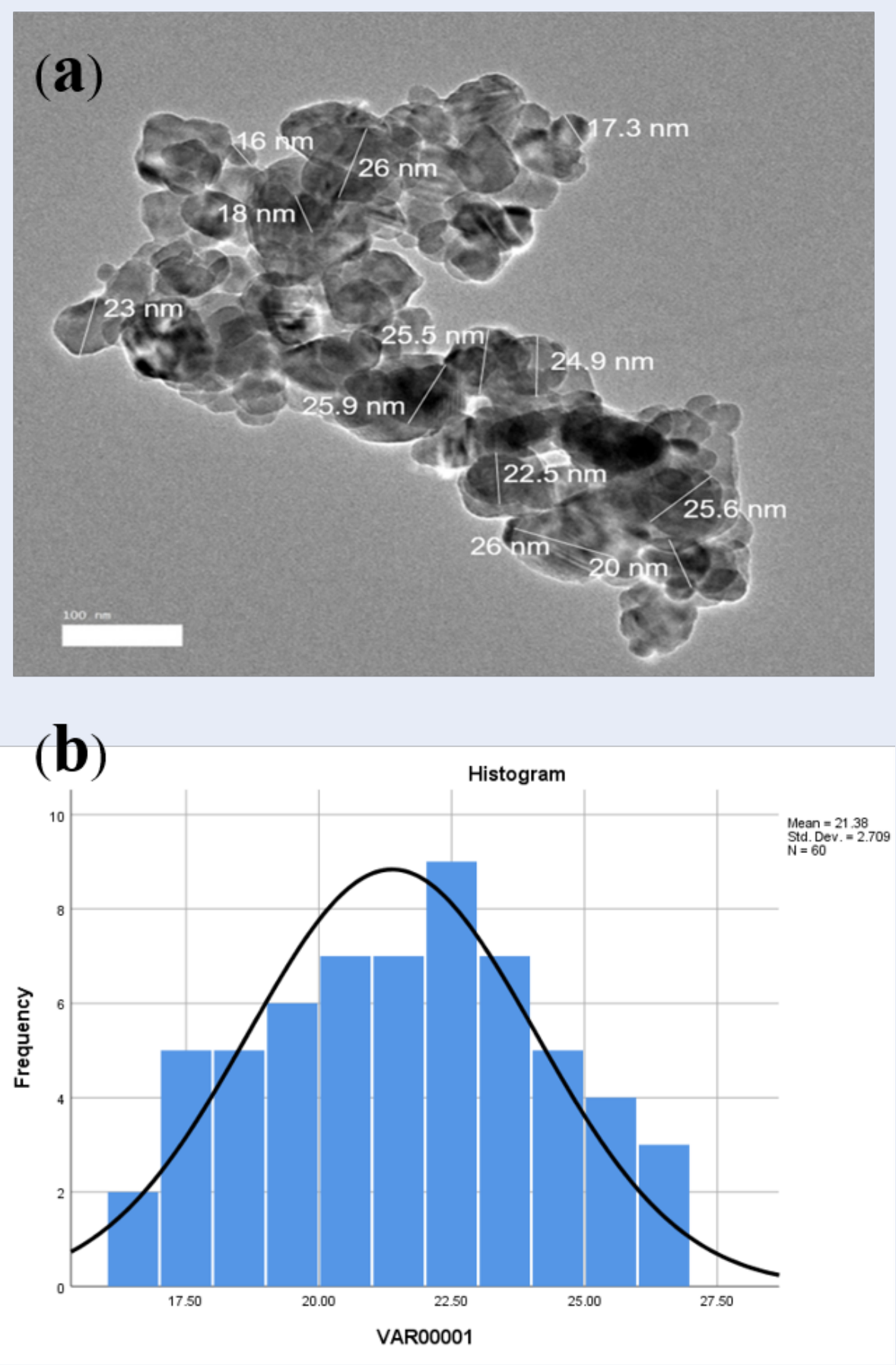

Figure 2: $\mathrm{CSCaCO}_{3} \mathrm{NP}$ (a) TEM micrograph of spherical-shaped $\mathrm{CSCaCO}_{3} \mathrm{NP}$; (b) A histogram showing the average diameter size of $\mathbf{2 1 . 3 8} \mathbf{n m}$ in distribution.

Table 5: The BJH desorption mean pore size and BET specific surface area of $\mathrm{CSCaCO}_{3} \mathrm{NP}$

\begin{tabular}{cccc}
\hline Sample & $\begin{array}{c}\text { BJH mean pore size } \\
\text { diameter }(\mathrm{nm})\end{array}$ & $\begin{array}{c}\text { Specific surface area BET } \\
\left(\mathrm{m}^{2} / \mathrm{g}\right)\end{array}$ & $\begin{array}{c}\text { The total volume of pores at } \\
\text { P/Po at } 0.9889\left(\mathrm{~cm}^{3} / \mathrm{g}\right)\end{array}$ \\
\hline $\mathrm{CSCaCO}_{3} \mathrm{NP}$ & 3.35 & $14.4806 \pm 0.110$ & 0.1211 \\
\hline
\end{tabular}



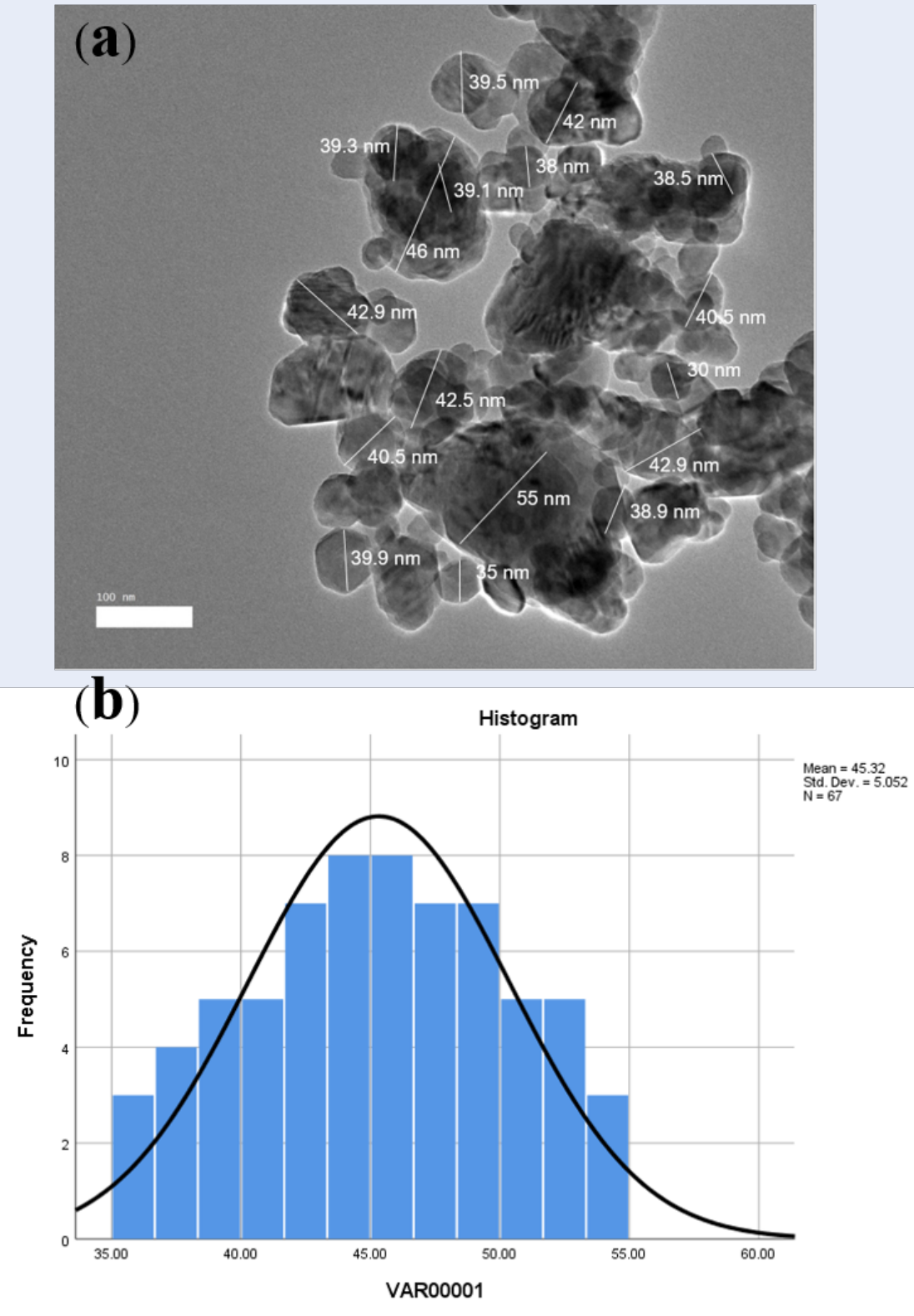

Figure 3: Cur-CSCaCO ${ }_{3} \mathrm{NP}$ : (a) TEM micrograph of spherical-shaped Cur-CSCaCO ${ }_{3} \mathrm{NP}$; (b) A histogram showing average diameter size of $\mathbf{4 5 . 3 2} \mathrm{nm}$ in distribution.

(24\%) and $\mathrm{pH} 7.4$ (40\%), when compared to the fast continuous release of free curcumin in $\mathrm{pH} 1.2(70 \%)$ at $24 \mathrm{hrs}$. Finally, the plateau phase lasted for $168 \mathrm{hrs,}$ accumulating to the following percentages of release of curcumin from Cur-CaCO $3 \mathrm{NP}$ : $\mathrm{pH} 4.8$ (64\%), $\mathrm{pH}$ $1.2(56 \%)$ and $\mathrm{pH} 7.4$ (78\%), when compared to the final release phase of free curcumin in $\mathrm{pH} 1.2$ (94\%). The data generated were fitted into three different kinetic equations and based on the co-efficient of determination $\left(\mathrm{R}^{2}\right)$ using linear regression analysis.
The Higuchi kinetic equation model $\left[\mathrm{pH} 7.4\left(\mathrm{R}^{2}=\right.\right.$ $0.9472)$ and $\left.\mathrm{pH} 1.2\left(\mathrm{R}^{2}=0.9632\right)\right]$ was the best fit when compared to the Korsmeyer-Peppas [pH 7.4 $\left(\mathrm{R}^{2}=0.9076\right)$ and $\left.\mathrm{pH} 1.2\left(\mathrm{R}^{2}=0.9615\right)\right]$ and Zero order $\left[\mathrm{pH} 7.4\left(\mathrm{R}^{2}=0.8067\right)\right.$ and $\left.\mathrm{pH} 1.2\left(\mathrm{R}^{2}=0.8513\right)\right]$ kinetic models, as shown in Figures 11 and 12.

\section{DISCUSSION}

Adopting an improved method of top-down development of $\mathrm{CSCaCO}_{3} \mathrm{NP}$ by previous literature, while 


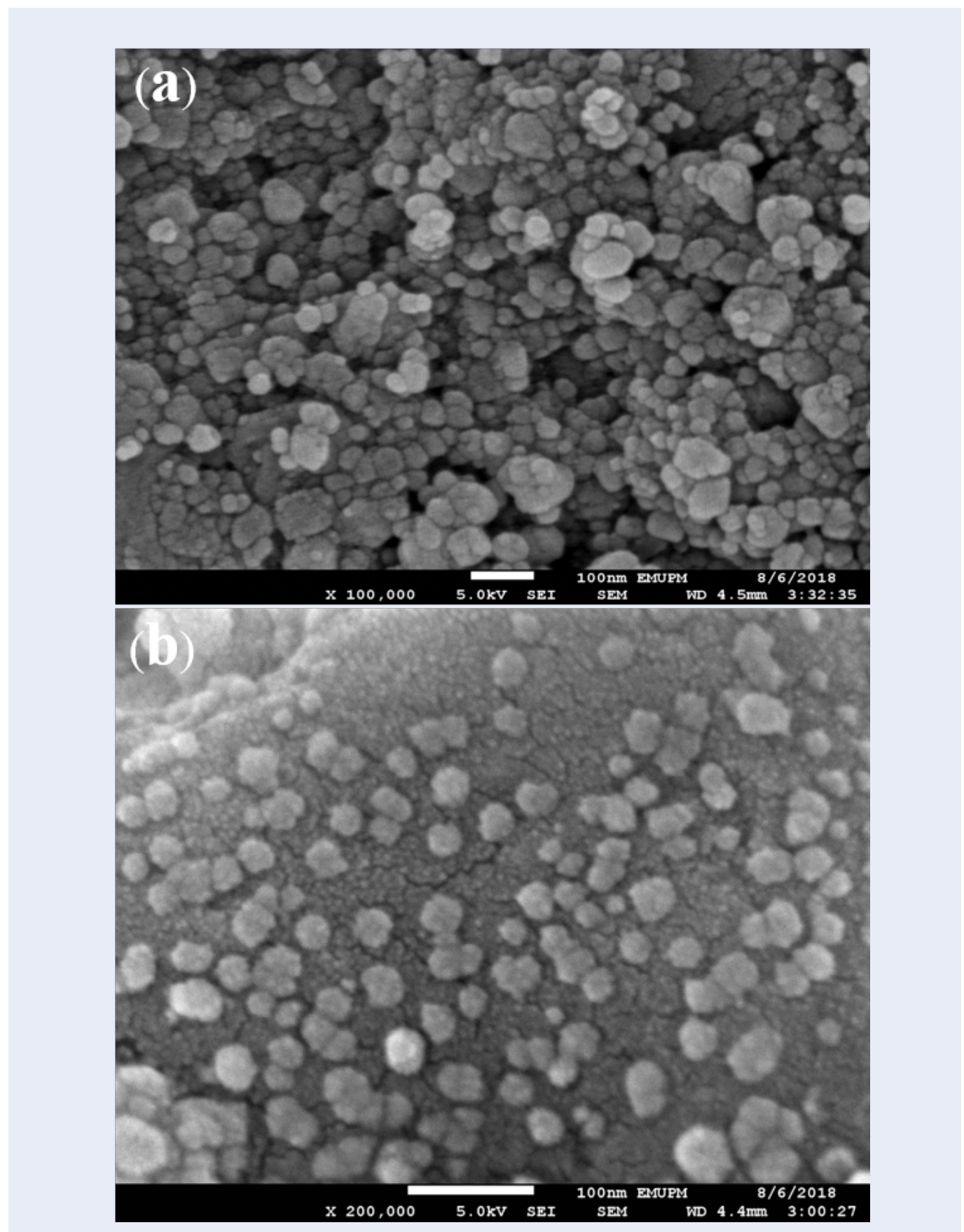

Figure 4: Cur-CSCaCO ${ }_{3} \mathrm{NP}$ : (a) TEM micrograph of spherical-shaped Cur-CSCaCO ${ }_{3} \mathrm{NP}$; (b) A histogram showing average diameter size of $\mathbf{4 5 . 3 2} \mathbf{n m}$ in distribution. 


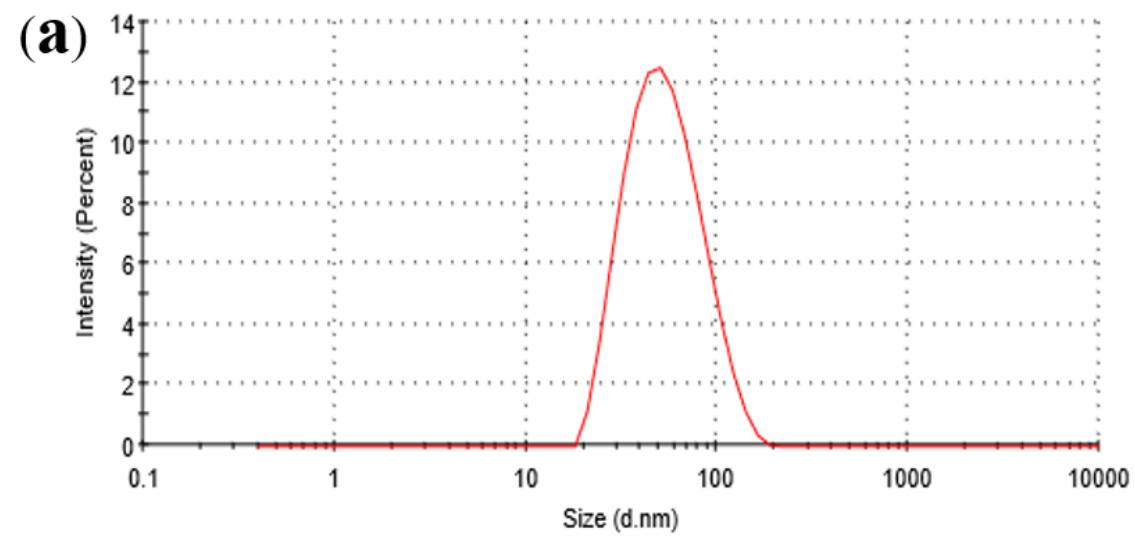

(b)

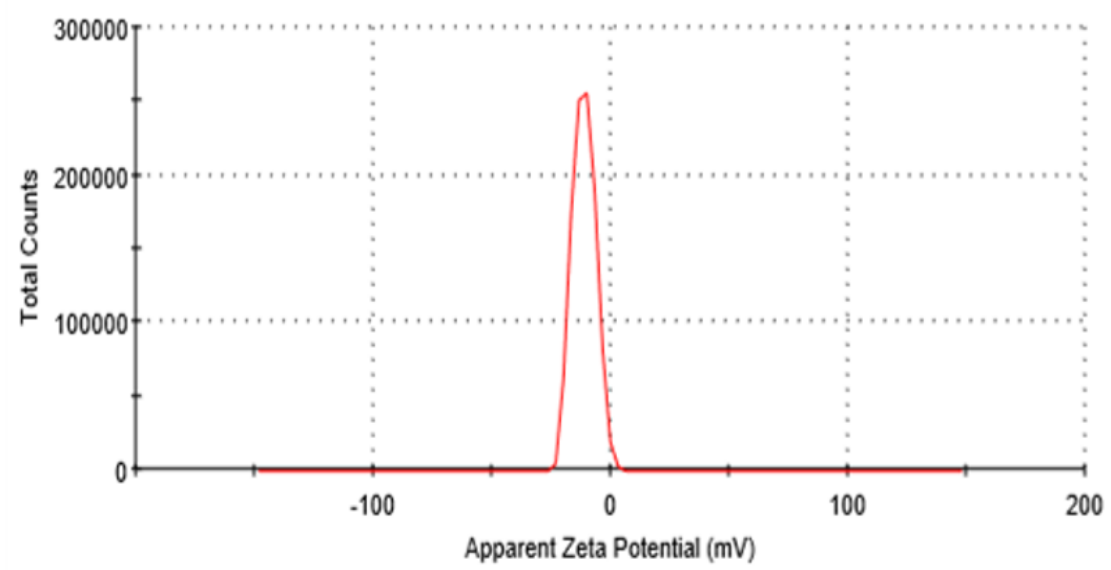

Figure 5: A graphical representation of $\mathrm{CSCaCO}_{3}$ NP showing: (a) An average mean diameter size of 50.09 $\pm 1.04 \mathrm{~nm}$ (b) Surface charge of $-18.7 \mathrm{mV}$.

improving other parameters therein (time, drying, temperature, and stirring speed) provided a better smaller size and larger surface area for the nanoparticles used in this study. The large surface area further supported the high loading content and encapsulation efficiency of CSCaCO3NP for curcumin and for the pore size volume obtained. In the current study, the entrapment of curcumin onto the newly synthesized nanocarrier significantly improved curcumin's solubility. Cur-CSCaCO${ }_{3} \mathrm{NP}$ demonstrated a sustained kinetic release with a better slow release pattern observed at $\mathrm{pH}$ 1.2, when compared to the sustained release profile observed at $\mathrm{pH} 7.4$ and free curcumin at $\mathrm{pH}$ 1.2. These observations showed that a large amount of curcumin was encapsulated into the matrix of $\mathrm{CSCaCO}_{3} \mathrm{NP}$, resulting in $\mathrm{pH}$ - and timedependent release patterns associated with the strong effect of the properties of curcumin. Moreover, the
Higuchi equation model best described the nature of the $\mathrm{CSCaCO}_{3} \mathrm{NP}$ release.

Although curcumin has poor solubility in aqueous medium, in the present study the loading of curcumin onto the newly synthesized nanocarrier increased its solubility. This is in agreement with earlier studies that reported enhanced curcumin solubility when loading onto nanocarriers ${ }^{29,32,40}$. Additionally, the higher encapsulation efficiency and loading capacity observed in all the different theoretical ratios of curcumin to nanoparticles, regardless of the differences in the ratio amounts, are suggestive of strong interactions of the curcumin molecules with $\mathrm{CSCaCO}_{3} \mathrm{NP}$. This is because the negatively charged $\mathrm{CSCaCO}_{3} \mathrm{NP}$ highly attracted the positively charged curcumin, and therefore, electrostatic attractions occurred $^{41}$. The ratio chosen for the subsequent anal- 

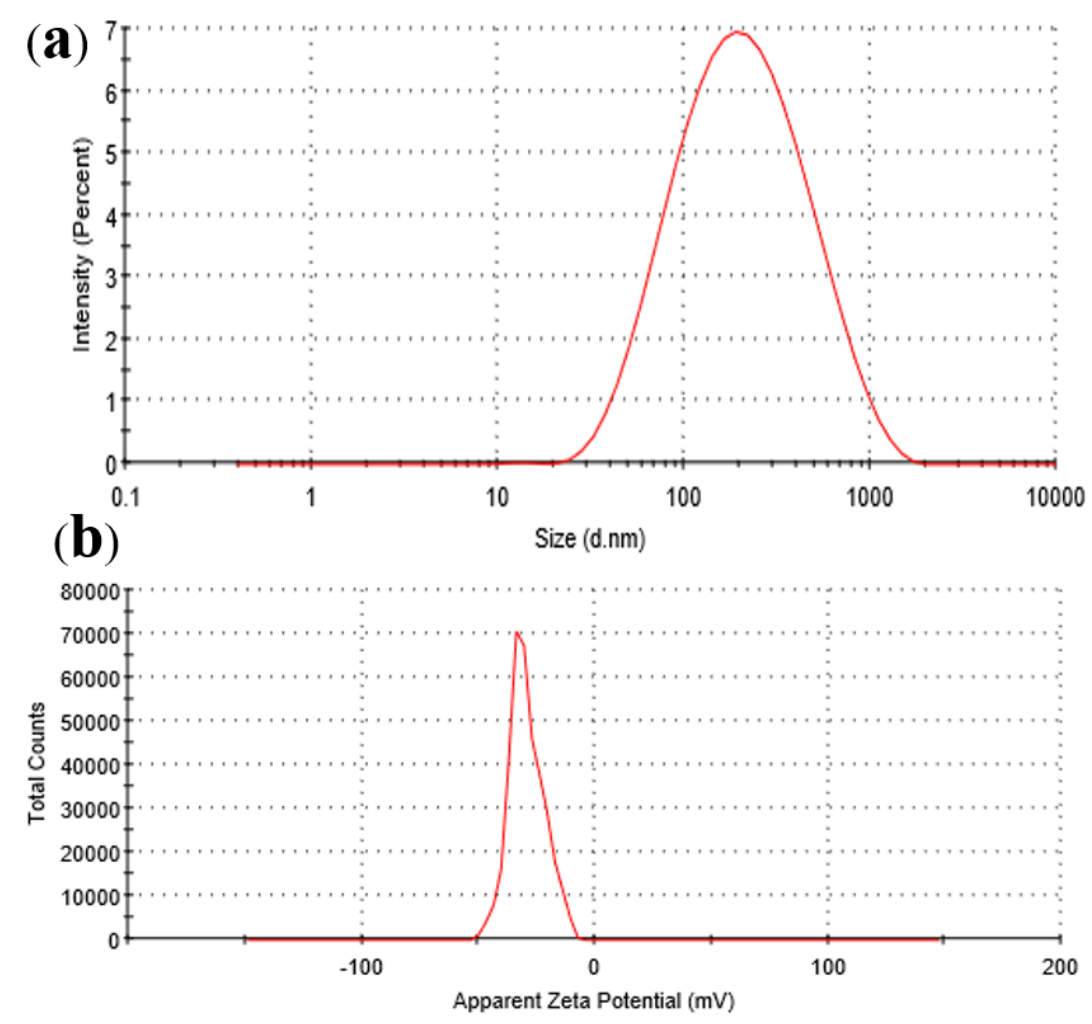

Figure 6: Agraphical representation of $\mathrm{Cur}_{-} \mathrm{CSCaCO}_{3} \mathrm{NP}$ showing: (a) Mean diameter size of $140.06 \pm 1.01$

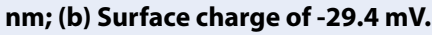

ysis in this study was due to the small amount of $\mathrm{CSCaCO}_{3} \mathrm{NP}$ used in encapsulating a high amount of curcumin. Hence, it provided a better optimum percentage suitable for the entrapment of curcumin in the core shell of the nanoparticles. This showed that few amounts of curcumin were lost during the loading process; thus, more curcumin molecules could interact with molecules of the nanoparticles, thereby resulting in a fair amount of curcumin being encapsulated $^{8,23,25}$. The findings of the present study, indeed, revealed less curcumin wastage and minimal usage of $\mathrm{CSCaCO}_{3} \mathrm{NP}$. Interestingly, $\mathrm{CSCaCO}_{3} \mathrm{NP}$ has been reported to exhibit nanopore features which give room for high loading capacity by means of capillary force interactions ${ }^{41-43}$. It can be deduced from this study that the EE \% decreases with a corresponding increase in the amount of curcumin, while LC \% increases with a corresponding decrease of curcumin. In the present study, a small mean diameter of $\mathrm{CSCaCO}_{3} \mathrm{NP}$ and Cur-CSCaCO $\mathrm{CP}_{3} \mathrm{NP}$ were produced, although there was presence of some agglomeration which is peculiar to $\mathrm{CaCO}_{3} \mathrm{NP}$ due to its hygroscopic nature; this is in concordance with previous studies where similar occurrences were reported ${ }^{44-46}$. The small mean diameter obtained could increase the oral bioavailability of curcumin since it is welldocumented that particle size reduction could increase drug efficacy and promote efficient interfacial interaction with the cell membrane, as a result of endocytosis of small-sized particles compared to larger ones ${ }^{47}$. However, particle size less than $5 \mathrm{~nm}$ is likely to be eliminated by the kidney before reaching their target site, while larger particle size above $200 \mathrm{~nm}$ quickly gets sequestered by the liver and spleen at the reticulo-endothelial system ${ }^{48}$. The size diameter obtained for $\mathrm{CSCaCO}_{3} \mathrm{NP}$ in this study falls within the effective range that could be administered for therapeutic purposes. In addition, nanoparticle of size < $200 \mathrm{~nm}$ showed an improved long period of circulation in the body and as well as a decrease in hepatic filtrations ${ }^{49}$. Although, this study recorded a double increase in the size of the nanoparticle after loading with curcumin, which is as a result of the amounts/ratios of the two compounds used during the loading process. 


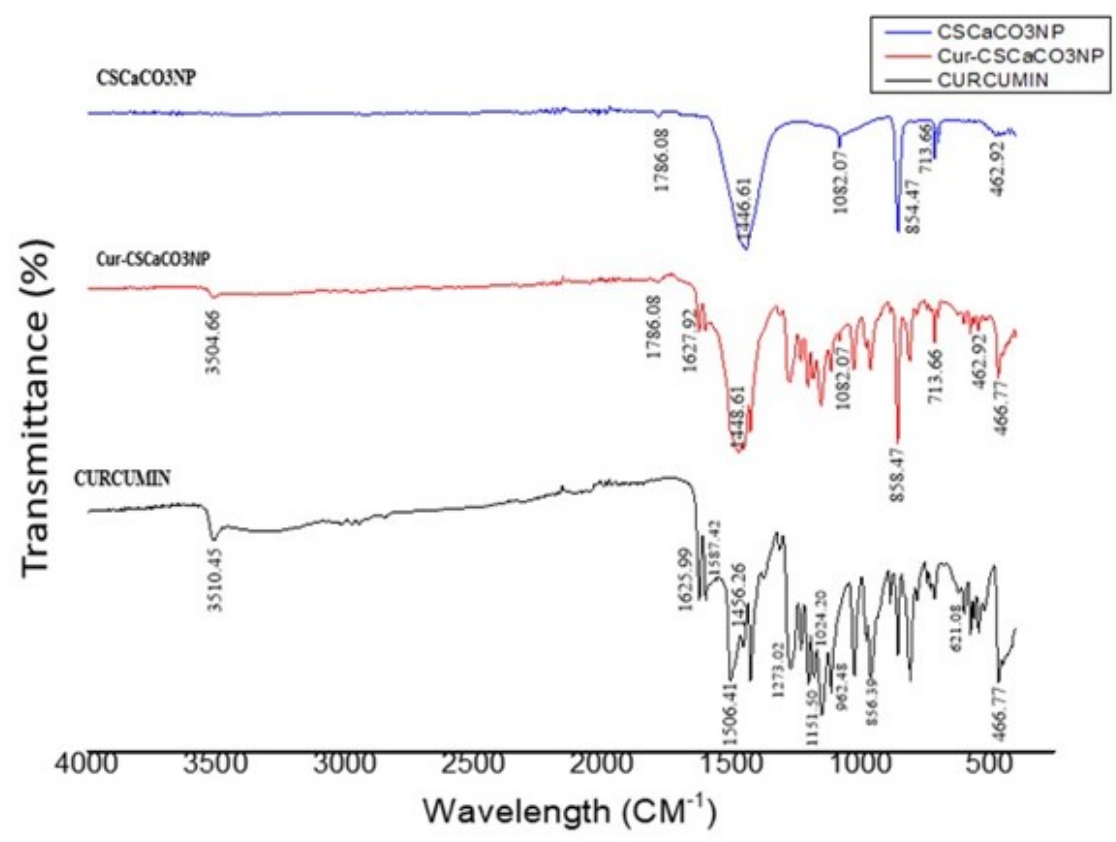

Figure 7: Agraphical representation of an elementary analysis showing the functional group endings of $\mathrm{CaCO}_{3} \mathrm{NP}$, Cur-CSCaCO ${ }_{3} \mathrm{NP}$, and curcumin.

This results in possibly higher entrapments of the smaller curcumin molecules at the core shell and surface of the nanoparticles, leading to an increase in size. The increase in size of the nanoparticles upon loading has been reported previously in the literature ${ }^{22,25,49}$. In our study, the sizes obtained for Cur-CSCaCO${ }_{3} \mathrm{NP}$ fell within the acceptable range for effective oral administration since better drug release control and better cell infiltration nature have so far been demonstrated by nanoparticles below $100 \mathrm{~nm}^{30}$. Interestingly, porosity was clearly observed on $\mathrm{CSCaCO}_{3} \mathrm{NP}$ which is likely a credit to the high loading and encapsulation efficiency recorded, which were all in agreement with the findings of other studies, after subjecting the nanoparticles to TEM machine for diameter size analysis $22,25,50,51$.

FE-SEM revealed the surface morphology of $\mathrm{CSCaCO}_{3} \mathrm{NP}$ before and after loading with curcumin to be uniform and spherically shaped. Contrary to our present findings, previous studies have reported a rod-like shape for $\mathrm{CSCaCO}_{3} \mathrm{NP}^{3,21,42}$. However, variation in the size and shape of nanomaterials may be influenced by the source of the biomaterial used and the method employed during the synthesis ${ }^{19,22,25}$. Spherically-shaped biogenic nanoparticles were reported to possess large surface areas for interactions with biological systems, thereby making them excellent nanocarriers ${ }^{22,25}$. Spherical nanoparticles were seen $500 \%$ efficiently taken up by cells, compared to the rod-shaped nanoparticles, due to the prolonged membrane engulfment time needed for the lengthy shaped nanoparticles ${ }^{52}$. Thus, these results suggest that the spherical shape obtained for $\mathrm{CSCaCO}_{3} \mathrm{NP}$ and $\mathrm{Cur}-\mathrm{CSCaCO}_{3} \mathrm{NP}$ in this study is suitable for the delivery of therapeutic agents. However, minute aggregations were observed before loading; this is due to the method adopted for the preparation of the sample for FE-SEM analysis, which allowed fast absorption of moisture from the environment ${ }^{51}$. The absence of aggregations after loading could be due to curcumin chemical properties being hydrophobic, which could slightly affect the hydrophilic nature of the nanoparticle and, thus, prevent it from absorbing moisture from the environment ${ }^{50}$.

The inherent polydispersity of nanoparticles influences any predictable contact behavior of the nanoparticles with cells ${ }^{9,50}$. While neutral functional groups are reported to effectively prevent the invading of unwanted nanomaterials into the biological system, the majority of the charged functional groups of nanoparticles greatly affects cellular interactions, thus serving as an excellent driving force for active nanoparticles to interact with cells ${ }^{53}$. The 


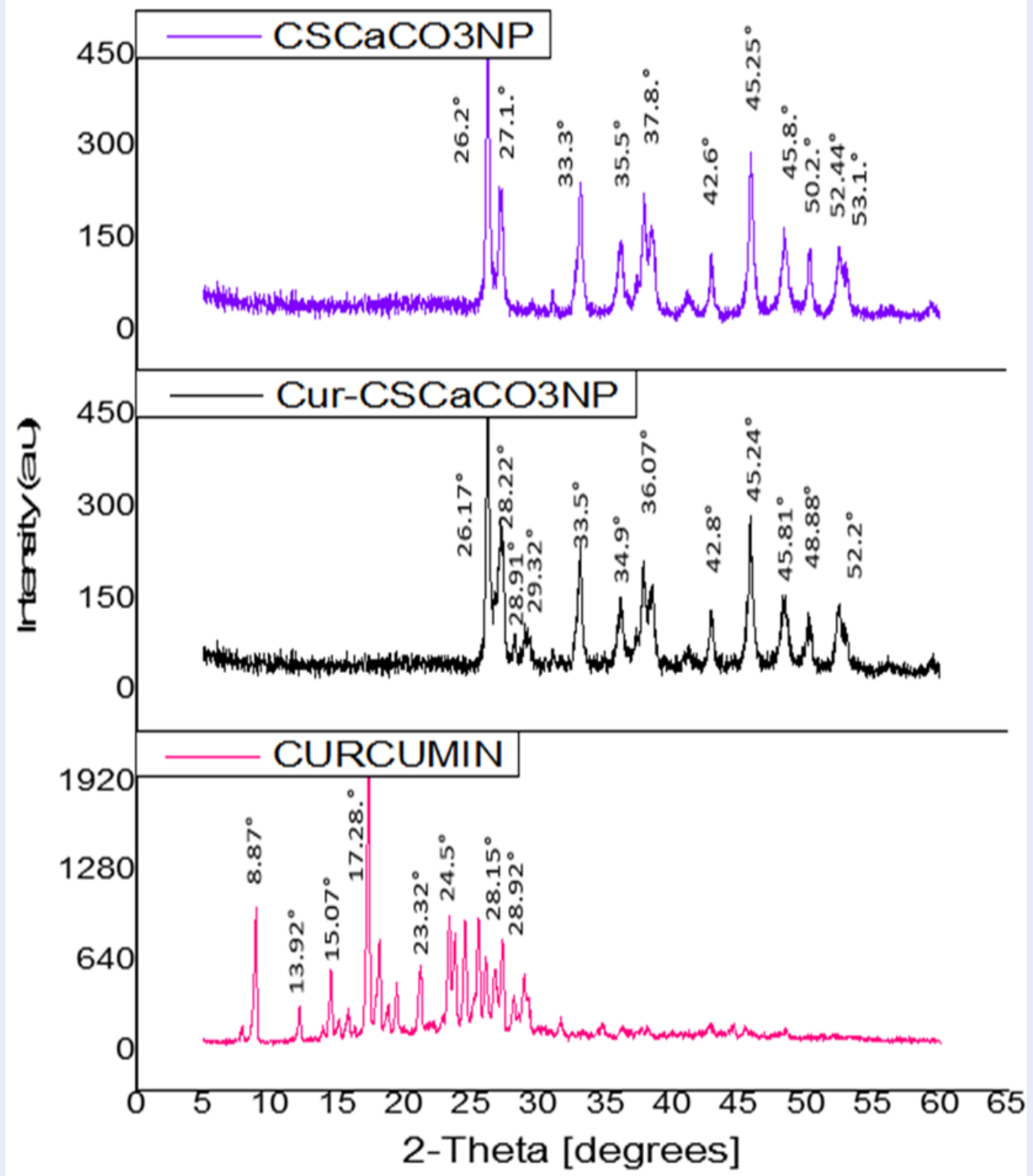

Figure 8: The XRD pattern (X-Ray diffraction spectra) of $\mathrm{CSCaCO}_{3} \mathrm{NP}, \mathrm{Cur}-\mathrm{CSCaCO}_{3} \mathrm{NP}$, and curcumin.

zeta sizer results in this study depicted that the net charge of the formulations was negative which provided a high affinity for curcumin during loading. As such, the charge potential increased after loading with curcumin which indicated strong stability and strong loading efficiency; this is in agreement with the work of Rejinold et al. ${ }^{31}$, who reported an increase in the charge potential of fibrinogen after loading with curcumin. The high negative charge obtained for both $\mathrm{CSCaCO}_{3} \mathrm{NP}$ and $\mathrm{Cur}-\mathrm{CSCaCO}_{3} \mathrm{NP}$ indicates the stability of the compounds, which is attributable to the strong electro-static repulsion be- tween the nanoparticles. Similar findings were reported in the literature ${ }^{9,42,54}$. The low PDI obtained is indicative of an excellent uniformity of the size distribution of the nanoparticles. An increase in the hydrodynamic diameter, seen in this study after loading, was perhaps a result of the drug fed onto the core shell of the nanoparticles as well as the surface attachment of the curcumin molecules to the nanoparticles, which led to an increase in nanoparticle size. Similar findings have been reported in previous studies ${ }^{29,55}$. Furthermore, the difference in the particle size observed with the nanocarrier on TEM and FESEM, 


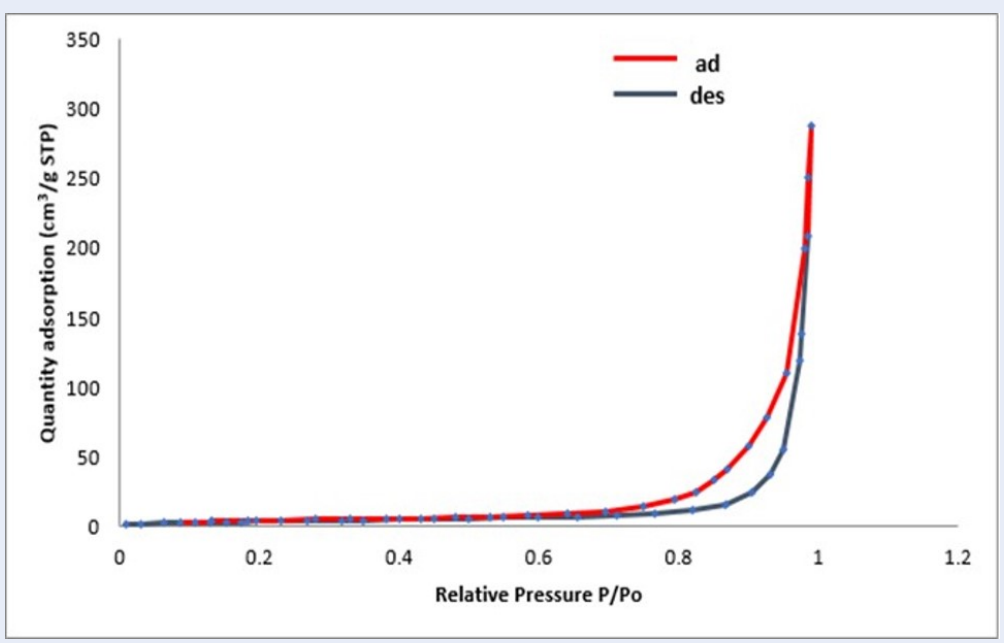

Figure 9: Brunauer-Emmett-Teller isotherm graph of $\mathrm{CSCaCO}_{3} \mathrm{NP}$.

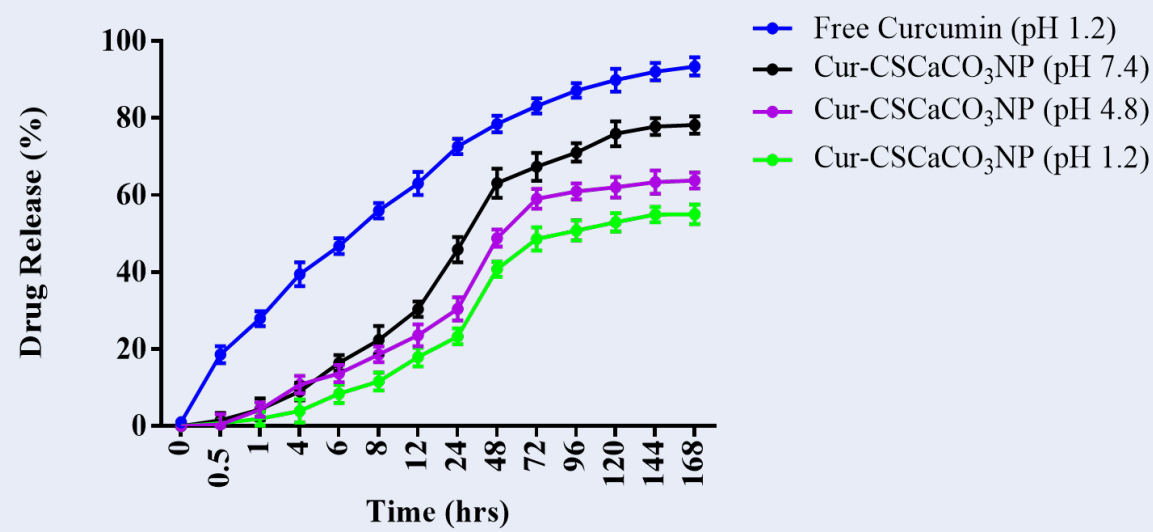

Figure 10: Cumulative release curves of free curcumin and $\mathrm{Cur}-\mathrm{CSCaCO}_{3} \mathrm{NP}$ in different pH media at different time points showing variations on the release of curcumin in vitro. Triplicate data and values are expressed in mean $\pm \operatorname{SEM}(n=3)$.

compared to the size obtained on hydrodynamic analyzer, were probably due to the water absorbed by the particles suspended in water, while the absolute dried samples were observed on the electron microscopes, as described by Lozano-Pérez et al. ${ }^{56}$ and Montalbán et al. ${ }^{29}$. Besides, the hydrophobic and electrostatic nature of the interaction between $\mathrm{CSCaCO}_{3} \mathrm{NP}$ and curcumin could result in high strong bonding at the core and surface attachment of the nanoparticles. However, these variations in size between electron microscopic measurement and hydrodynamic analyzer could be attributable to the presence of strong electrostatic repulsion between the nanoparticles in hydrodynamic motion during measurement ${ }^{46}$. Another possible reason could be due to the influence of agglomeration tendency on the size distribution of the particles in motion due to the increase seen in the PDI of the particle after loading ${ }^{57}$. Similarly, previous findings have documented size variations when different techniques were adopted $29,36,46$. Thus, TEM and FESEM measure the diameter of the particle in real time with the simple principle of the electron beam with a single particle measured, while the hydrodynamic analyzer uses the principles of both hydrodynamic and light. High positive or negative values of zeta potential above $\pm 30 \mathrm{mV}$ for the nanoparticles indicates excellent stability and averts particle agglomeration due to electrostatic stabilization ${ }^{22,43}$. This may explain the aggregation observed in this 


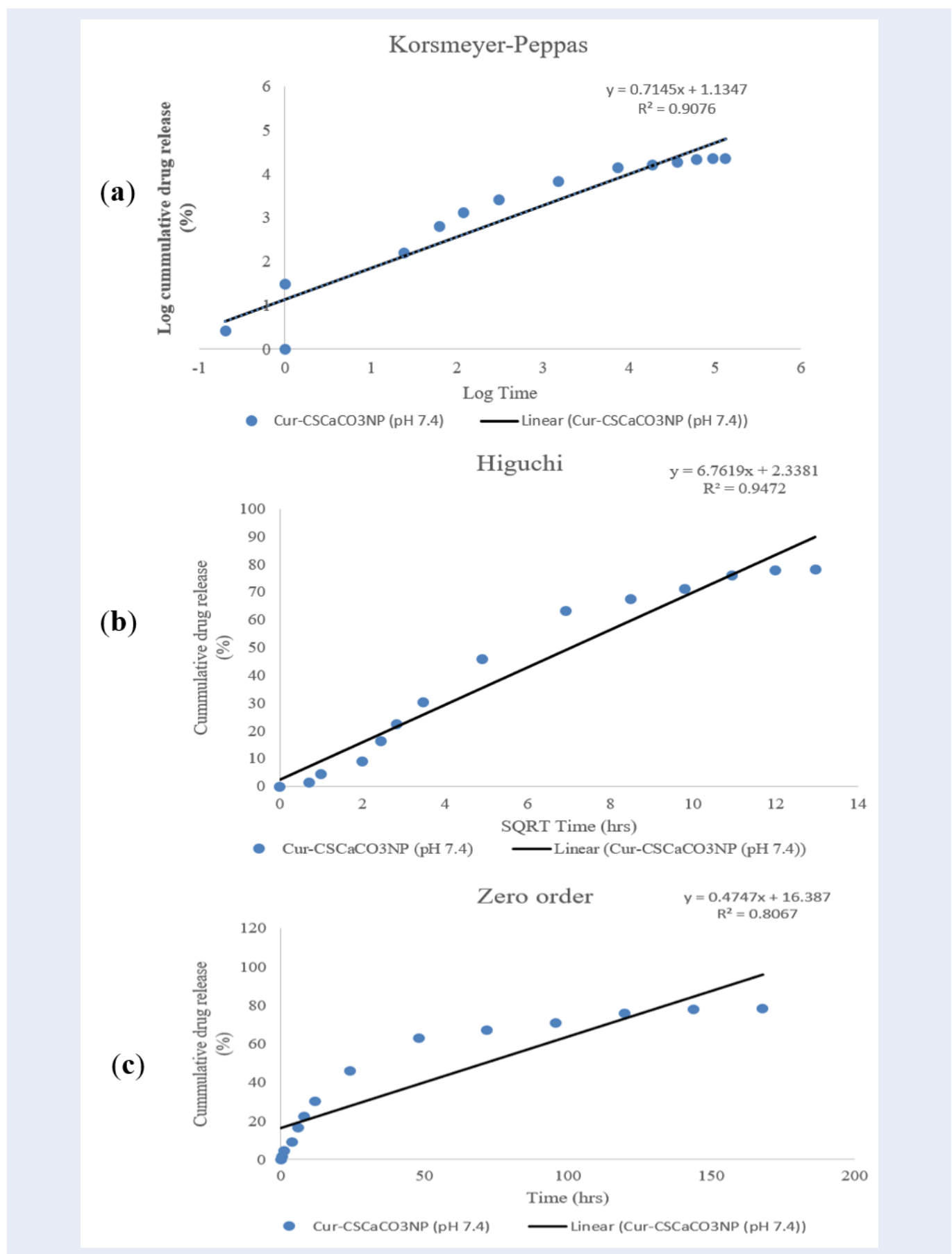

Figure 11: Fitting experimental data of $\mathrm{Cur}-\mathrm{CSCaCO}_{3} \mathrm{NP}$ release in pH 7.4 medium by: (a) Korsmeyer-peppas release model, (b) Higuchi release model, and (c) Zero order release model. 
(a)

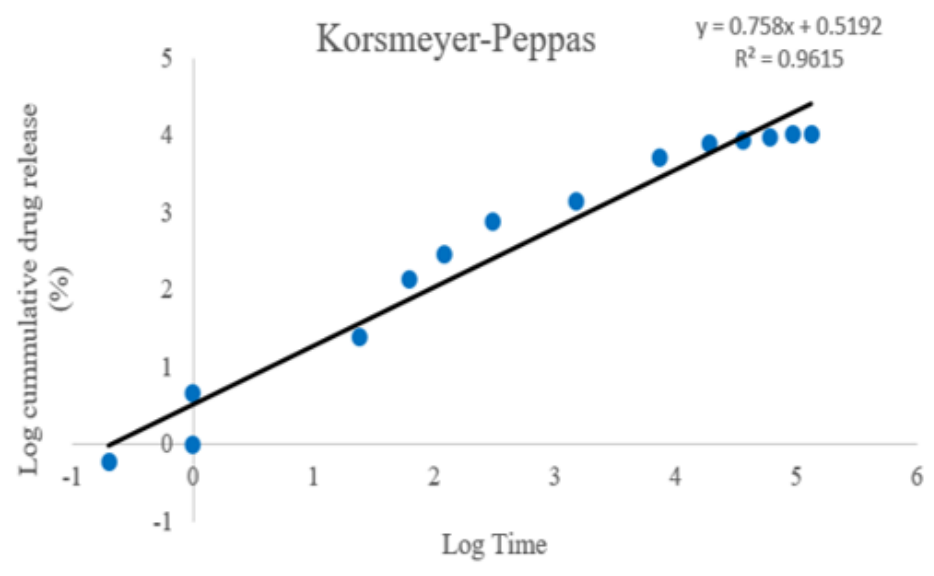

- Cur-CSCaCO3NP (pH 1.2) - Linear (Cur-CSCaCO3NP (pH 1.2))

Higuchi $\quad \mathrm{y}=4.9517 \mathrm{x}-1.2472$
$\mathrm{R}^{2}=0.9632$

(b)

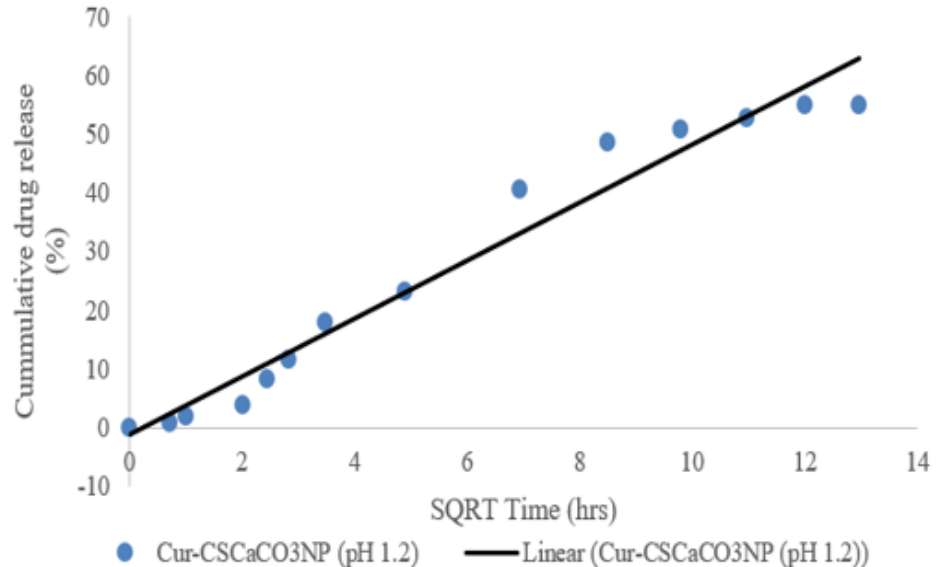

(c)

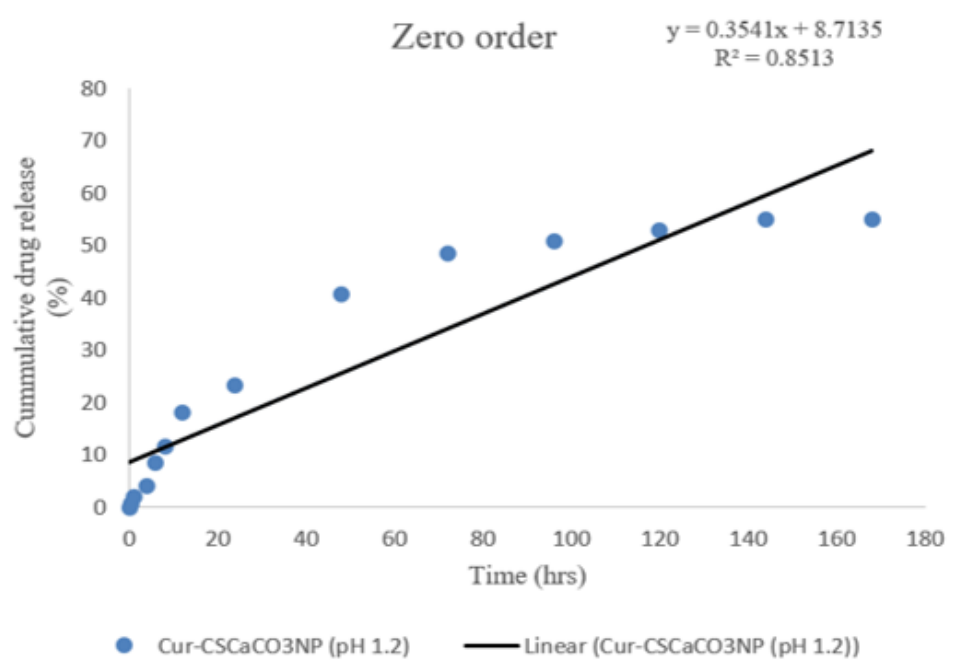

Figure 12: Fitting experimental data of $\mathrm{Cur}-\mathrm{CSCaCO}_{3} \mathrm{NP}$ release in pH 1.2 medium by: (a) Korsmeyer-peppas release model, (b) Higuchi release model, and (c) Zero order release model. 
study, which possibly led to the increase in nanoparticle size.

The FT-IR analysis proved the encapsulation of curcumin by $\mathrm{CSCaCO}_{3}$ aragonite nanoparticles in this study. The characteristic peaks shown by $\mathrm{CSCaCO}_{3} \mathrm{NP}$ are within the ranges of the aragonite spectra peaks. The peaks were described to be the peaks of $\mathrm{CO}_{3}{ }^{2-}$ which correspond to the v1-v4 vibrations with little structural changes. This is attributable to the shift of the carbonate vibrations in the milieu of oxygen atoms and the modification in the electrostatic valence force that exists in the $\mathrm{Ca}$ $\mathrm{O}$ bond ${ }^{58,59}$. Moreover, the sharp peak at 1082.07 $\mathrm{cm}^{-1}$ signifies the characteristic aragonite phase of the $\mathrm{CaCO}_{3}$ spectrum where ions are vague in the infrared region, as reported in past studies ${ }^{19,22}$. The band at $1446.61 \mathrm{~cm}^{-1}$ indicates $\mathrm{C}=\mathrm{C}$ stretching frequency, and $854.47 \mathrm{~cm}^{-1}$, and $713.66 \mathrm{~cm}^{-1}$ bands indicate the presence of carbonate $\left(\mathrm{CO}_{3}{ }^{2-}\right)$ explicitly. These findings are similar to previously documented findings ${ }^{19,22,25,58}$. Less noticeable characteristic reductions on the band were seen in the stretching frequency of Cur-CSCaCO 3 NP, which depicted slight negligible shifts in the peak of the curcumin spectrum, which is due to the bond formation between the two compounds after curcumin encapsulation. Meanwhile, the absence of any great shift of the $\mathrm{CSCaCO}_{3} \mathrm{NP}$ on the Cur- $\mathrm{CSCaCO}_{3} \mathrm{NP}$ spectrum suggests that the aragonite nanoparticle phase is intact and unaltered during the drug loading process. These were all in accordance with the work of Fu et al. ${ }^{23}$, who reported negligible shifts of the aragonite band when loaded with doxorubicin. Thus, this further explains the wavelength shift from the higher to lower region of the frequency, as previously suggested by Rejinold et al. ${ }^{31}$. In addition, the presence of curcumin-typical peaks, as shown on the loaded nanoparticles, reveals an effective loading of curcumin onto the aragonite nanoparticles. The out-of-plane bending and symmetric stretching correspond to different functional groups. The spectra peak of curcumin at $1627.92 \mathrm{~cm}^{-1}$ and 1427.32 $\mathrm{cm}^{-1}$ depicts $\mathrm{C}=\mathrm{C}$ stretching, $1456.26 \mathrm{~cm}^{-1}$ represents the $\mathrm{C}=\mathrm{H}$ (which is a result of olefinic bending vibration of the benzene ring), the absorption at peak $1151.50 \mathrm{~cm}^{-1}$ indicates a $\mathrm{C}-\mathrm{H}$ stretching, and the peak spectra at $1024.20 \mathrm{~cm}^{-1}$ may be due to the $\mathrm{C}-\mathrm{N}$ stretch. The peak at $1506.41 \mathrm{~cm}^{-1}$ is a result of the functional group of a benzene ring with a bond of C-O-C. However, the strong and most important ring of the benzene ring at $1506.41 \mathrm{~cm}^{-1}$ represented in the free curcumin peaks is completely absent on the Cur-CSCaCO${ }_{3} \mathrm{NP}$ spectra, indicating that free curcumin was loaded successfully onto $\mathrm{CSCaCO}_{3} \mathrm{NP}$. These results correspond with previous findings of co-encapsulation of curcumin and doxorubicin in poly(butyl cyanoacrylate) nanoparticles and chitosan ${ }^{59}$, an achievable loading of curcumin onto polymeric nanoparticles ${ }^{36}$, and nanocurcumin physicochemical fabrication ${ }^{60}$. However, some important shifts are confirmed on the spectra of Cur$\mathrm{CSCaCO}_{3} \mathrm{NP}$, including the shift peak from 1600.92 $\mathrm{cm}^{-1}$ to $1602.85 \mathrm{~cm}^{-1}$, and a shift of $1427.32 \mathrm{~cm}^{-1}$ to $1429.25 \mathrm{~cm}^{-1}$. The peaks at $1273.02 \mathrm{~cm}^{-1}$ and $856.39 \mathrm{~cm}^{-1}$ for the vibration of $\mathrm{C}-\mathrm{O}$ in $-\mathrm{C}-\mathrm{OCH} 3$ of the phenyl ring were shifted to $1274.95 \mathrm{~cm}^{-1}$ and $858.47 \mathrm{~cm}^{-1}$, respectively. Thus, they are all in accordance with the results of Rachmawati et al. ${ }^{61}$, and all the aforementioned strong peaks of curcumin concur with those described previously in the literature ${ }^{29,36}$. In the present study, the XRD pattern of the strong sharp peaks of free curcumin appeared to be absent on the Cur- $\mathrm{CSCaCO}_{3} \mathrm{NP}$ phase, which suggests that the free curcumin was strongly entrapped and encapsulated at the nanocore of $\mathrm{CSCaCO}_{3}$ NP. Furthermore, the absence of the sharp endothermic peaks of curcumin at $8^{\circ}-23.5^{\circ}$ regions of the Cur- $\mathrm{CSCaCO}_{3} \mathrm{NP}$ phase strongly suggests stability, purity, and solubility of the loaded nanoparticles (since successful incorporation of curcumin at $\mathrm{CSCaCO}_{3} \mathrm{NP}$ matrix was confirmed). These findings are in agreement with previous findings which explain the absence or negligence of any changes in the crystallinity phase of the loaded nanoparticles, compared with the blank $\mathrm{CSCaCO}_{3} \mathrm{NP}^{8,22,43}$. In addition, Karri et al. ${ }^{62}$ have reported the absence of strong peaks of curcumin that led to a change of the crystallinity nature of curcumin into an amorphous state after conjugation with chitosan nanoparticles.

In this study, $\mathrm{CSCaCO}_{3} \mathrm{NP}$ crystalline peaks were maintained after loading with free curcumin which promoted the sustained release of curcumin from the loaded nanoparticles. These findings are in accordance with the work of Kamba et al. ${ }^{42}$ and Hammadi et al. ${ }^{25}$, who reported the prominent peaks of $\mathrm{CSCaCO}_{3} \mathrm{NP}$ at 2 thetas $26.5^{\circ}, 27^{\circ}$, and $33.3^{\circ}$, respectively, and Wang et al. ${ }^{63}$ who documented the sharp peaks of free curcumin within the range of $10^{\circ} 30^{\circ}$. Despite the absence of the majority of the signal sharp peaks seen on the peaks of Cur- $\mathrm{CSCaCO}_{3} \mathrm{NP}$, in this study only a few peaks of curcumin were observed after loading. This confirms an earlier statement that the entrapment of curcumin was done predominantly at the core shell of the nanoparticles with few at the surface attachments. 
In the current study, in vitro release assessment of curcumin at different $\mathrm{pH}$ values was carried out to ensure consistency for the steady release of curcumin when passing through the gastrointestinal tract to the other parts of the body, when administered orally. The overall phases of curcumin release from $\mathrm{CSCaCO}_{3} \mathrm{NP}$ indicated high stability of the system in all the different $\mathrm{pH}$ environments used, indicating that curcumin was well-retained onto the core shell of the nanoparticles ${ }^{8}$. Jain and Jain ${ }^{64}$ had described the final slow and steady release rate to be attributed to proper localization and entrapment of drugs at the inner core of the nanoparticles. However, in this study, the initial release observed after $30 \mathrm{~min}$ in all the $\mathrm{pH}$ media could be a result of the excessive attachment of curcumin onto the large surface area of the nanoparticle, thereby causing those residues to be stacked at the edge of the membrane bag when tying. Thus, this promotes the initial dissolution of the weakly bound curcumin molecules. This is in accordance with previously reported findings ${ }^{64}$. The high release pattern of free curcumin in acidic $\mathrm{pH} 1.2$, from the initial to final stage, is due to the absence of the carrier medium, as reported by Chen et al. ${ }^{65}$. Thus, direct contact of curcumin with the acidic environment could lead to a fast release in the absence of a carrier medium. Perhaps, this would explain why orally-ingested curcumin suffers from quick digestion and rapid metabolism in the body, as documented earlier ${ }^{9,46}$.

In contrast, the slow and steady release of curcumin from $\mathrm{CSCaCO}_{3} \mathrm{NP}$ at $\mathrm{pH} 1.2$ means that curcumin loaded at the core shell of the nanocarrier could hardly be released in the gastric medium and so could easily bypass the fast digestion in the GI tract with help from the nanocarrier. This is in accordance with the previous reports ${ }^{9,60,65}$. Thus, $\mathrm{CSCaCO}_{3} \mathrm{NP}$ could not be rapidly digested at the GI tract by digestive enzymes but rather slowly degraded by enzymes released by the bacterial flora present in the intestine, which is consistent with previous reports ${ }^{51}$ which have revealed the optimum retention of $\mathrm{CaCO}_{3}$ nanomaterials (derived from egg shells) at $\mathrm{pH} \mathrm{1.2,} \mathrm{when} \mathrm{compared} \mathrm{to}$ the rapid degradation and fast release at $\mathrm{pH}$ 7.4. Indeed, the particles could be retained in the stomach then transit to the intestine for proper final release and absorption. Besides, Udompornmongkol and Chiang $^{36}$ reported only $2 \%$ release pattern of curcumin from polymeric nanoparticle at $\mathrm{pH} 1.2$, compared to $80 \%$ release at $\mathrm{pH}$ 4.5. Furthermore, the influence of the nature of the loaded drug cannot be left out during the release mechanism; indeed, curcumin undergoes rapid degradation in both neutral and basic
$\mathrm{pH}$ environments as compared to acidic $\mathrm{pH}$ environment ${ }^{65,66}$. In addition, this release behaviour is consistent with Shao et al's ${ }^{67}$ experimental results relating to ganoderma lucidum polysaccharide release; the authors observed a slow release at $\mathrm{pH} 1.7$ as compared to the release at $\mathrm{pH} 7.4$, and further explained the possible ionization of carboxylic group at higher $\mathrm{pH}$, thus resulting in an increase in electrostatic repulsion which causes the polymer to loosen.

Of note, a markedly high cumulative percentage of drug release from $\mathrm{CSCaCO}_{3} \mathrm{NP}$ was observed in $\mathrm{pH}$ 4.8 compared to $\mathrm{pH} 7.4$ as reported by other scientists $^{25,54,68}$, thus contrary to our current findings. However, the other authors did not assess the release pattern at $\mathrm{pH} 1.2$, which is a stronger acidic medium than the $\mathrm{pH}$ medium they used $(\mathrm{pH} 4.8)$, and they failed to provide data on the fate of $\mathrm{CSCaCO}_{3} \mathrm{NP}$ in strong acidic medium irrespective of the different candidate drugs used. In our study, the high percentage of curcumin release, observed at $\mathrm{pH} 7.4$ when compared to the percentage release at $\mathrm{pH} 1.2$ and $\mathrm{pH}$ 4.8 , was due to the maximally sustained release of curcumin. Therefore, the release of the loaded curcumin at $\mathrm{pH} 1.2$ indicates high stability of Cur- $\mathrm{CSCaCO}_{3} \mathrm{NP}$, and thus curcumin can be protected from acidic stomach content when orally administered. However, apart from the protective effect of the nanocarrier for curcumin, the stability of curcumin was reported at low $\mathrm{pH}$ condition, attributable to its conjugated diene structure; likewise, the instability of curcumin in neutral to basic media is based on the removal of its proton from the phenolic group, leading to its structural destruction ${ }^{69}$. The release pattern seen in the study herein is in accordance with the work of Render et al. ${ }^{51}$ and Rejinold et al. ${ }^{31}$. Based on the observed sustained release pattern in strong acidic medium, it can be deduced that the therapeutic efficacy of orallyadministered curcumin may be improved by encapsulation with $\mathrm{CSCaCO}_{3} \mathrm{NP}$ since the therapeutic efficacy of every encapsulated drug is directly proportional to the quantity of the drug released from the carrier system $^{70}$. Further, there is a high tendency for efficient uptake of Cur- $\mathrm{CSCaCO}_{3} \mathrm{NP}$ by the cells at the upper GI tract before reaching the GI tract proper to prevent possible contact with the gastric content, which may aid in quick degradation and prolong circulation of the soluble curcumin in the blood, which will, in turn, improve curcumin bioavailability. In the present study, the results of the kinetic models demonstrated the nature of the overall release of curcumin from $\mathrm{CSCaCO}_{3} \mathrm{NP}$. Among the three mathematical models, the Higuchi kinetic release best fits the release kinetics of $\mathrm{Cur}-\mathrm{CSCaCO}_{3} \mathrm{NP}$. Thus, 
it can be deduced that the release kinetic of Cur$\mathrm{CSCaCO}_{3} \mathrm{NP}$ was due to the effect of the diffusion rate and slow degradation of the cockle shell nanomaterial. This could be possible because the Higuchi equation model describes the release kinetics as consequences of dissolution and diffusion rates ${ }^{71}$. In respect to this, the mechanisms of curcumin release from the mesoporous surface and layered matrix of $\mathrm{CSCaCO}_{3} \mathrm{NP}$ involve the simultaneous penetration of $\mathrm{pH}$ medium, dissolution of curcumin, and gradual leaching out of curcumin through $\mathrm{CSCaCO}_{3} \mathrm{NP}$ interstitial pores. $\mathrm{CSCaCO}_{3} \mathrm{NP}$ poses numerous porosity with multiple layers ${ }^{22}$. Thus, $\mathrm{Cur}-\mathrm{CSCaCO}_{3} \mathrm{NP}$ in the respective $\mathrm{pH}$ medium initially releases curcumin via diffusion at a rate proportional to the square root of time, before the gradual and complete degradation of Cur- $\mathrm{CSCaCO}_{3} \mathrm{NP}$ for proper curcumin release. Indeed, Cur- $\mathrm{CSCaCO}_{3} \mathrm{NP}$ release mechanism obeys the Higuchi model release manner; this model of drug release of curcumin from other nanoparticles was reported earlier in previous studies ${ }^{38,39,72,73}$.

\section{CONCLUSION}

In the current study, spherical-shaped $\mathrm{CSCaCO}_{3} \mathrm{NP}$ were successfully synthesized using a low cost, environmental-friendly, and simple topdown method. Conjugation of curcumin with $\mathrm{CSCaCO}_{3} \mathrm{NP}$ with excellent loading capacity was also successful. Curcumin was encapsulated with a substantial release in vitro as shown in Figure 13. A slow and substantial release of curcumin from $\mathrm{CSCaCO}_{3} \mathrm{NP}$ was observed at $\mathrm{pH} 1.2$ compared to the rapid sustained release of curcumin at $\mathrm{pH}$ 7.4 , suggesting that $\mathrm{Cur}-\mathrm{CaCO}_{3} \mathrm{NP}$ could hardly be released in the gastric medium. The release data were fitted well in the Higuchi equation model, indicating that the release of curcumin from $\mathrm{CSCaCO}_{3} \mathrm{NP}$ was controlled by diffusion and slow degradation mechanisms. Therefore, $\mathrm{CSCaCO}_{3} \mathrm{NP}$ shows promise in promoting bioavailability and stability of curcumin, while reducing the insolubility of free curcumin, for effective oral delivery of curcumin in therapeutic applications. Additionally, the in vivo practical application of newly synthesized Cur- $\mathrm{CaCO}_{3} \mathrm{NP}$ against lead-induced cerebral damage in animal models is currently ongoing by the research team to evaluate the in vivo therapeutic efficacy of Cur- $\mathrm{CSCaCO}_{3} \mathrm{NP}$.

\section{ABBREVIATIONS}

$\mathrm{CSCaCO}_{3} \mathrm{NP}$ : Cockle shell calcium carbonate nanoparticles

Cur- $\mathrm{CSCaCO}_{3}$ NP: Curcumin loaded- Cockle shell calcium carbonate nanoparticles
PDI: Polydispersity Index

IR: Immediate release

GIT: Gastrointestinal tracts

$\mathrm{CaCO}_{3}$ : Calcium carbonate

XRD: X-ray diffractometer

BET: Brunauer-Emmett-teller

TEM: Transmission electron microscope

FT-IR: Fourier Transform Infrared Rays

FE-SEM: Field emission scanning electron microscope

EE\%: Percentage encapsulation efficiency

LE\%: Percentage loading efficiency

BS-12: Dodecyl dimethyl betaine

BJH: Barrett-Joyner-halenda

hrs: Hours

$\mu \mathbf{m}$ : Micrometer.

\section{CONFLICTS OF INTEREST}

The authors declare no conflict of interest.

\section{AUTHOR CONTRIBUTIONS}

All authors contributed to the drafting of this manuscript. "conceptualization, M.M.M.; M.A.M.M. and Z.A.B.Z.; methodology M.M.M.; A.D.; M.A.M.M.; E.B.A.R and Z.A.B.Z., validation, M.M.M.; A.D.; and Z.A.B.Z.; formal analysis M.M.M.; A.D. and M.A.M.M. investigation, M.M.M.; K.A.; A.D.; M.A.M.M.; and Z.A.B.Z.; data curation, M.M.M.; A.D; writing-original draft preparation, M.M.M.; writing-review and editing, M.M.M.; K.A.; A.D.; S.M.C.; supervision, E.B.A.R.; M.A.M.M. and Z.A.B.Z.

\section{ACKNOWLEDGMENT}

The authors would like to acknowledge Universiti $\mathrm{Pu}$ tra Malaysia for funding this research project (Grant number GP-IPS 9663600).

\section{REFERENCES}

1. Stupp SI, Braun PV. Molecular Manipulation of Microstructures: Biomaterials, Ceramics, and Semiconductors. Science. 1997;277(5330):1242-1248.

2. Jain D, Banerjee R. Comparison of ciprofloxacin hydrochloride-loaded protein, lipid, and chitosan nanoparticles for drug delivery. Journal of Biomedical Materials Research Part B, Applied Biomaterials. 2008;86(1):105-12. PMID: 18098198. Available from: 10.1002/jbm.b.30994.

3. Islam KN, Bakar MZ, Noordin MM, Hussein MZ, Rahman NS, Ali ME. Bin; Rahman, N. S. B. A.; Ali, M. E. Characterisation of Calcium Carbonate and Its Polymorphs from Cockle Shells (Anadara Granosa). Powder Technology. 2011;213(1):188-91. Available from: 10.1016/j.powtec.2011.07.031.

4. Ma L, Zhao G, Fang Y, Dai W, Ma N. Facile Synthesis of Mesoporous Calcium Carbonate Particles with Finger Citron Residue as Template and Their Adsorption Performances for Congo Red. Adsorption Science and Technology. 2018;36(34):872-87. Available from: 10.1177/0263617417727228. 


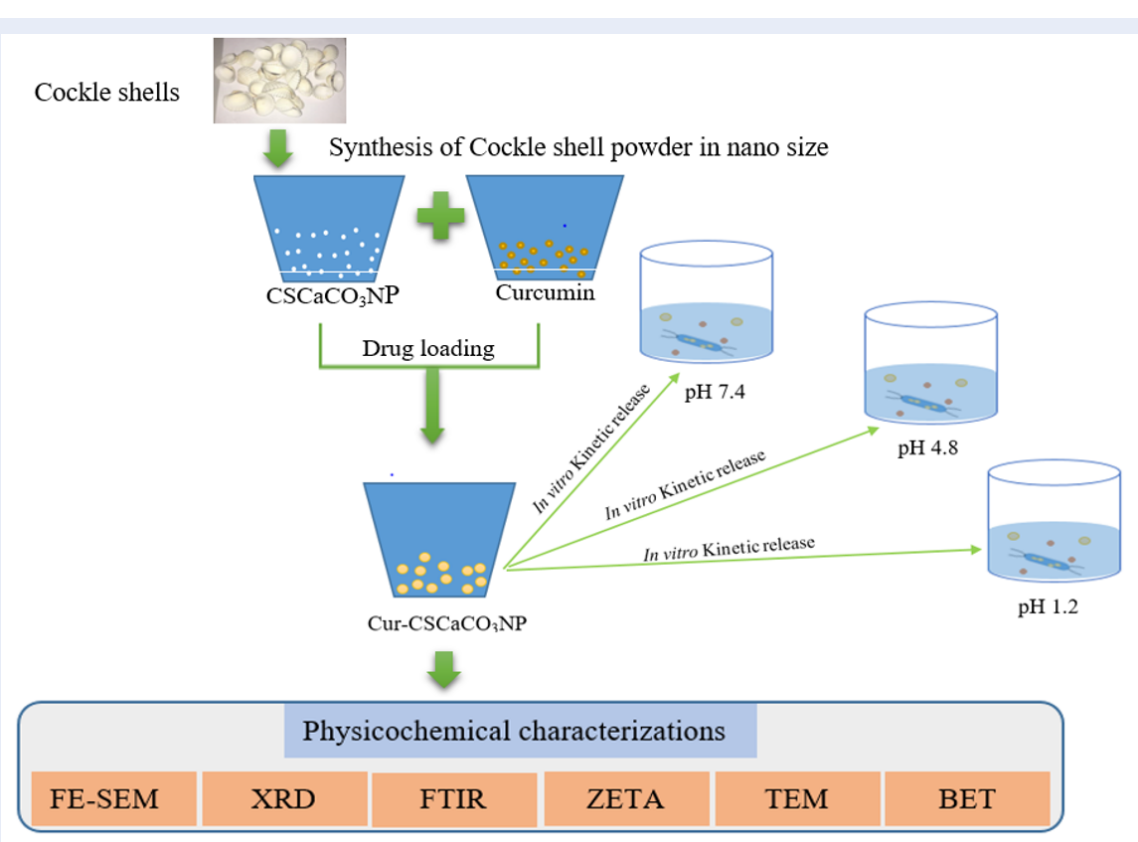

Figure 13: Diagrammatic representation of the synthesis, characterization and in vitro kinetic release mechanism of Cur-CSCaCO ${ }_{3}$ NP.

5. Giner-Casares JJ, Henriksen-Lacey M, Coronado-Puchau M, Liz-Marzán LM. Inorganic Nanoparticles for Biomedicine: Where Materials Scientists Meet Medical Research. Materials Today. 2016;19(1):19-28. Available from: 10.1016/j.mattod. 2015.07.004.

6. Ghafar SLMA, Hussein MZ, Zakaria ZAB. Synthesis and Characterization of Cockle Shell-Based Calcium Carbonate Aragonite Polymorph Nanoparticles with Surface Functionalization. J Nanoparticles. 2017;2017:1-12. Available from: 10.1155/2017/ 8196172.

7. Bhawana, Basniwal RK, Buttar HS, Jain VK, Jain N. Curcumin nanoparticles: preparation, characterization, and antimicrobial study. Journal of Agricultural and Food Chemistry. 2011;59(5):2056-61. PMID: 21322563. Available from: $10.1021 /$ if104402t

8. Ji S, Lin X, Yu E, Dian C, Yan X, Li L, et al. Curcumin-Loaded Mixed Micelles: Preparation, Characterization, and in Vitro Antitumor Activity. Journal of Nanotechnology. 2018;2018:9. Available from: 10.1155/2018/9103120

9. Kumar A, Ahuja A, Ali J, Baboota S. Curcumin-loaded lipid nanocarrier for improving bioavailability, stability and cytotoxicity against malignant glioma cells. Drug Delivery. 2016;23(1):214-29. PMID: 24825490. Available from: 10.3109/ 10717544.2014.909906.

10. Sharma RA, Gescher AJ, Steward WP. Curcumin: the story so far. European Journal of Cancer (Oxford, England). 2005;41(13):1955-68. PMID: 16081279. Available from: 10. 1016/j.ejca.2005.05.009.

11. Takagi T, Ramachandran C, Bermejo M, Yamashita S, Yu LX, Amidon GL. A provisional biopharmaceutical classification of the top 200 oral drug products in the United States, Great Britain, Spain, and Japan. Molecular Pharmaceutics. 2006;3(6):631-43. PMID: 17140251. Available from: 10.1021/ mp0600182.

12. Kawabata $Y$, Wada $K$, Nakatani $M$, Yamada $S$, Onoue $S$. Formulation design for poorly water-soluble drugs based on biopharmaceutics classification system: basic approaches and practical applications. International Journal of Pharmaceutics. 2011;420(1):1-10. PMID: 21884771. Available from: $10.1016 / \mathrm{j}$. ijpharm.2011.08.032.

13. Hörter D, Dressman J. Influence of Physicochemical Properties on Dissolution of Drugs in the Gastrointestinal Tract. Advanced Drug Delivery Reviews. 2002;46(13):75-87. PMID: 11259834.

14. Cheng AL, Hsu CH, Lin JK, Hsu MM, Ho YF, Shen TS, et al. Anticancer Res. 2001;21(4B):2895-900. PMID: 11712783.

15. Anand $P$, Kunnumakkara $A B$, Newman RA, Aggarwal $B B$ Bioavailability of curcumin: problems and promises. Molecular Pharmaceutics. 2007;4(6):807-18. PMID: 17999464. Available from: $10.1021 / \mathrm{mp} 700113 \mathrm{r}$.

16. Marslin G, Prakash J, Qi S, Franklin G. Oral Delivery of Curcumin Polymeric Nanoparticles Ameliorates CCl4-Induced Subacute Hepatotoxicity in Wistar Rats. Polymers. 2018;10(5):541. PMID: 30966575. Available from: 10.3390/polym10050541.

17. Sahari F, Mijan NA. Cockle Shell As An Alternative Construction Material For Artificial Reef. In: International Conference on Creativity and Innovation for Sustainable Development, International Islamic University Malaysia, KL; 2011.

18. Torchilin VP. Nanocarriers. Pharmaceutical Research. 2007;24(12):2333-4. PMID: 17934800. Available from: 10 . 1007/s11095-007-9463-5.

19. Jaji AZ, Bakar MZ, Mahmud R, Loqman MY, Hezmee MN, Isa $T$, et al. Synthesis, characterization, and cytocompatibility of potential cockle shell aragonite nanocrystals for osteoporosis therapy and hormonal delivery. Nanotechnology, Science and Applications. 2017;10:23-33. PMID: 28176933. Available from: 10.2147/NSA.S113030.

20. Mailafiya MM, Abubakar K, Danmaigoro A, Chiroma SM, Bin E, Rahim A. Cockle Shell-Derived Calcium Carbonate (Aragonite) Nanoparticles: A Dynamite to Nanomedicine. Applied Sciences (Basel, Switzerland). 2019;9(14):2894.

21. Hoque ME. Processing and Characterization of Cockle Shell Calcium Carbonate (CaCO3) Bioceramic for Potential Application in Bone Tissue Engineering. Journal of Marine Science and Engineering. 2014;02(04):2-6. 
22. Danmaigoro A, Selvarajah GT, Noor MH, Mahmud R, Zakaria MZ. Development of Cockleshell (Anadara Granosa) Derived CaCO3nanoparticle for Doxorubicin Delivery. Journal of Computational and Theoretical Nanoscience. 2017;14(10):507486. Available from: $10.1166 /$ jctn.2017.6920.

23. Fu W, Noor MHM, Yusof LM, Ibrahim TA, Keong YS, Jaji AZ, et al. In Vitro Evaluation of a Novel PH Sensitive Drug Delivery System Based Cockle Shell-Derived Aragonite Nanoparticles against Osteosarcoma. Journal of Experimental Nanoscience. 2017;12(May):1-22. Available from: 10.1080/17458080.2017. 1287965.

24. Isa T, Zuki $A B$, Rukayadi $Y$, Mohd NM, Jaji AZ, Imam MU. N. I. H. and S. K. M. Antibacterial Activity of CiprofloxacinEncapsulated Cockle Shells Calcium Carbonate (Aragonite) Nanoparticles and Its Biocompatability In. Int J Mol Sci Artic. 2016;17:713. Available from: 10.3390/ijms17050713.

25. Hammadi NI, Abba Y, Hezmee MN, Razak IS, Jaji AZ, Isa $T$, et al. Formulation of a Sustained Release Docetaxel Loaded Cockle Shell-Derived Calcium Carbonate Nanoparticles against Breast Cancer. Pharmaceutical Research. 2017;34(6):1193-203. PMID: 28382563. Available from: 10 1007/s11095-017-2135- 1 .

26. Hamidu A, Mokrish A, Mansor R, Razak IS, Danmaigoro A, Jaji $A Z$, et al. Modified methods of nanoparticles synthesis in $\mathrm{pH}$-sensitive nano-carriers production for doxorubicin delivery on MCF-7 breast cancer cell line. International Journal of Nanomedicine. 2019;14:3615-27. PMID: 31190815. Available from: 10.2147/IJN.S190830.

27. Jaji AZ, Zakaria ZA, Mahmud R, Loqman MY, Hezmee MN, Abba $Y$, et al. Safety assessments of subcutaneous doses of aragonite calcium carbonate nanocrystals in rats. Journal of Nanoparticle Research. 2017;19(5):175. PMID: 28553160. Available from: 10.1007/s11051-017-3849-z.

28. Danmaigoro A, Selvarajah GT, Noor MHM, Mahmud R, Bakar MZA. Toxicity and Safety Evaluation of Doxorubicin-Loaded Cockleshell-Derived Calcium Carbonate Nanoparticle in Dogs. Adv Pharmacol Sci . 2018;2018. Available from: 10.1155/2018/ 4848602.

29. Montalbán MG, Coburn JM, Lozano-Pérez AA, Cenis JL, VílIora G, Kaplan DL. Production of Curcumin-Loaded Silk Fibroin Nanoparticles for Cancer Therapy. Nanomaterials (Basel, Switzerland). 2018;8(2):126. PMID: 29495296. Available from: $10.3390 /$ nano8020126.

30. Karri VV, Kuppusamy G, Talluri SV, Mannemala SS, Kollipara R, Wadhwani AD, et al. Curcumin loaded chitosan nanoparticles impregnated into collagen-alginate scaffolds for diabetic wound healing. International Journal of Biological Macromolecules. 2016;93:1519-29. PMID: 27180291. Available from: 10.1016/j.ijbiomac.2016.05.038.

31. Rejinold NS, Muthunarayanan M, Chennazhi KP, Nair SV, Jayakumar R. Curcumin loaded fibrinogen nanoparticles for cancer drug delivery. Journal of Biomedical Nanotechnology. 2011;7(4):521-34. PMID: 21870456. Available from: $10.1166 /$ jbn.2011.1320.

32. Bisht S, Feldmann G, Soni S, Ravi R, Karikar C, Maitra A. Polymeric nanoparticle-encapsulated curcumin nanocurcumin: a novel strategy for human cancer therapy. Journal of Nanobiotechnology. 2007;5(1):3. PMID: 17439648. Available from: 10.1186/1477-3155-5-3.

33. Chirio D, Peira E, Dianzani C, Muntoni E, Gigliotti CL, Ferrara B, et al. Development of Solid Lipid Nanoparticles by Cold Dilution of Microemulsions: Curcumin Loading, Preliminary In Vitro Studies, and Biodistribution. Nanomaterials (Basel, Switzerland). 2019;9(2):230. PMID: 30744025. Available from: 10.3390/nano9020230.

34. Athira GK, Jyothi AN. Preparation and Characterization of Curcumin Loaded Cassava Starch Nanoparticles with Improved Cellular Absorption. International Journal of Pharmacy and Pharmaceutical Sciences. 2014;6(10):171-6.

35. Islam KN, Bakar MZ, Ali ME, Hussein MZ, Noordin MM, Loqman MY, et al. Bin; Noordin, M. M.; Loqman, M. Y.; Miah, G.; Wahid, H.; Hashim, U. A Novel Method for the Synthesis of Calcium Carbonate (Aragonite) Nanoparticles from Cockle Shells. Powder Technology. 2013;235:70-5. Available from: 10.1016/j.powtec.2012.09.041.

36. Udompornmongkol $\mathrm{P}$, Chiang BH. Curcumin-loaded polymeric nanoparticles for enhanced anti-colorectal cancer applications. Journal of Biomaterials Applications. 2015;30(5):537-46. PMID: 26170212. Available from: $10.1177 / 0885328215594479$.

37. Jahromi MAM, Al-Musawi S, Pirestani M, Ramandi MF, Ahmadi $\mathrm{K}$, Rajayi $\mathrm{H}$, et al. Curcumin-Loaded Chitosan Tripolyphosphate Nanoparticles as a Safe,Natural and Effective Antibiotic Inhibits the Infection of Staphylococcusaureus and Pseudomonas Aeruginosa in Vivo. Iranian Journal of Biotechnology. 2014;12(3):1-8. Available from: 10.15171/ijb.1012.

38. Anish H. Verma, T.S Sampath Kumar, K. Madhumathi, Y. Rubaiya, Murugan Ramalingan, and M. D. Curcumin Releasing Eggshell Derived Carbonated. Journal of Nanoscience and Nanotechnology. 2019;19(11):6872-80. PMID: 31039839.

39. Kar S, Kundu B, Reis RL, Sarkar R, Nandy P, Basu R, et al. Curcumin ameliorates the targeted delivery of methotrexate intercalated montmorillonite clay to cancer cells. European Journal of Pharmaceutical Sciences. 2019;135(135):91-102. PMID: 31078644. Available from: 10.1016/j.ejps.2019.05.006.

40. Shaikh J, Ankola DD, Beniwal V, Singh D, Kumar MN. Nanoparticle encapsulation improves oral bioavailability of curcumin by at least 9-fold when compared to curcumin administered with piperine as absorption enhancer. European Journal of Pharmaceutical Sciences. 2009;37(3-4):223-30. PMID: 19491009. Available from: 10.1016/j.ejps.2009.02.019.

41. Wang C, Liu Y, Bala H, Pan Y, Zhao J, Zhao X, et al. Facile Preparation of $\mathrm{CaCO} 3$ nanoparticles with Self-Dispersing Properties in the Presence of Dodecyl Dimethyl Betaine. Colloids and Surfaces A, Physicochemical and Engineering Aspects. 2007;297(1-3):179-82. Available from: 10.1016/j.colsurfa.2006. 10.045 .

42. Kamba AS, Ismail M, Ibrahim TAT, Zakaria ZA. Synthesis and Characterisation of Calcium Carbonate Aragonite Nanocrystals from Cockle Shell Powder (Anadara Granosa). Journal of Nanomaterials. 2013;2013:9. Available from: 10.1155/2013/ 398357.

43. Isa $T$, Zakaria ZA, Rukayadi $Y$, Hezmee MNM, Jaji AZ, Imam MU, et al. Antibacterial Activity of Ciprofloxacin-Encapsulated Cockle Shells Calcium Carbonate (Aragonite) Nanoparticles and Its Biocompatability in Macrophage J774A.1. International Journal of Molecular Sciences. 2016;17(5):713. PMID: 27213349. Available from: 10.3390/ijms17050713.

44. Dizaj SM, Barzegar-Jalali M, Zarrintan MH, Adibkia K, Lotfipour F. Calcium carbonate nanoparticles as cancer drug delivery system. Expert Opinion on Drug Delivery. 2015;12(10):164960. PMID: 26005036. Available from: 10.1517/17425247.2015. 1049530.

45. Ghaji MS, Abu Z, Zakaria B, Shameha AR, Noor M, Hezmee $M$, et al. Novelty to Synthesis Nanoparticles from Cockle Shall via Mechanical Method to Delivery and Controlled Release of Cytarabine. Journal of Computational and Theoretical Nanoscience. 2017;14:1-9.

46. Kiranda HK, Mahmud R, Abubakar D, Zakaria ZA. Fabrication, Characterization and Cytotoxicity of Spherical-Shaped Conjugated Gold-Cockle Shell Derived Calcium Carbonate Nanoparticles for Biomedical Applications. Nanoscale Research Letters. 2018;13(1):1-10. PMID: 29299709. Available from: 10.1186/s11671-017-2411-3.

47. Ghadi A, Mahjoub S, Tabandeh F, Talebnia F. Synthesis and optimization of chitosan nanoparticles: potential applications in nanomedicine and biomedical engineering. Caspian Journal of Internal Medicine. 2014;5(3):156-61. PMID: 25202443.

48. Kura AU, Hussein MZ, Fakurazi S, Arulselvan P. Layered double hydroxide nanocomposite for drug delivery systems; biodistribution, toxicity and drug activity enhancement. Chemistry Central Journal. 2014;8(1):47. PMID: 25177361. Available from: 10.1186/s13065-014-0047-2. 
49. Bhatia S. Natural Polymer Drug Delivery Systems: Nanoparticles. Switzerland: Springer International Publishing; 2016. Available from: 10.1007/978-3-319-41129-3.

50. Priyadarsini KI. The chemistry of curcumin: from extraction to therapeutic agent. Molecules (Basel, Switzerland). 2014;19(12):20091-112. PMID: 25470276. Available from: 10.3390/molecules191220091.

51. Render D, Samuel T, King H, Vig M, Jeelani S, Babu RJ, et al. Biomaterial-Derived Calcium Carbonate Nanoparticles for Enteric Drug Delivery. J Nanomater. 2016;2016. Available from: $10.1155 / 2016 / 3170248$.

52. Jiang W, Kim BY, Rutka JT, Chan WC. Nanoparticle-mediated cellular response is size-dependent. Nature Nanotechnology. 2008;3(3):145-50. PMID: 18654486. Available from: 10.1038/ nnano.2008.30.

53. Verma A, Stellacci F. Effect of surface properties on nanoparticle-cell interactions. Small. 2010;6(1):12-21. PMID: 19844908. Available from: 10.1002/smll.200901158.

54. Kamba SA, Ismail M, Hussein-Al-Ali SH, Ibrahim TA, Zakaria ZA In vitro delivery and controlled release of Doxorubicin for targeting osteosarcoma bone cancer. Molecules (Basel, Switzerland). 2013;18(9):10580-98. PMID: 23999729. Available from: 10.3390/molecules180910580.

55. Gendelman HE, Anantharam V, Bronich T, Ghaisas S, Jin H, Kanthasamy AG, et al. Nanoneuromedicines for degenerative, inflammatory, and infectious nervous system diseases. Nanomedicine (London). 2015;11(3):751-67. PMID: 25645958. Available from: 10.1016/j.nano.2014.12.014.

56. Lozano-Pérez AA, Ana L. Gil, Sergio A. Pérez, Natalia Cutillas, Hajo Meyer, Mónica Pedreño, Salvador Aznar-Cervantes, Christoph Janiak, Jose Luis Cenis, and J. R. Silk Fibroin Nanoparticles: Efficient Vehicles for the Natural Antioxidant Quercetin. International Journal of Pharmaceutics. 2017;25(1\{-\}2):11-9.

57. Boonyuen S, Malaithong M, Prokaew A. Decomposition Study of Calcium Carbonate in Shell. Thai J Sci Technol. 2015;4(2):115-22.

58. Raju CL, Narasimhulu KV, Gopal NO, Rao JL, Reddy BC. Electron Paramagnetic Resonance, Optical and Infrared Spectral Studies on the Marine Mussel Arca Burnesi Shells. Journal of Molecular Structure. 2002;608(2-3):201-11. Available from: 10.1016/S0022-2860(01)00952-8.

59. Duan J, Mansour HM, Zhang Y, Deng X, Chen Y, Wang J, et al. Reversion of multidrug resistance by co-encapsulation of doxorubicin and curcumin in chitosan/poly(butyl cyanoacrylate) nanoparticles. International Journal of Pharmaceutics. 2012;426(1-2):193-201. PMID: 22274587. Available from: 10.1016/j.ijpharm.2012.01.020.

60. Pandit RS, Gaikwad SC, Agarkar GA, Gade AK, Rai M. Curcumin Nanoparticles: Physico-Chemical Fabrication and Its in Vitro Efficacy against Human Pathogens. 3 Biotech. 2015;5(6):991997.

61. Rachmawati H, Yanda YL, Rahma A, Mase N. Curcumin-Loaded PLA Nanoparticles: Formulation and Physical Evaluation. Scientia Pharmaceutica. 2016;84(1):191-202. PMID: 27110509. Available from: 10.3797/scipharm.ISP.2015.10.
62. Karri VV, Kuppusamy G, Talluri SV, Mannemala SS, Kollipara R, Wadhwani AD, et al. Curcumin loaded chitosan nanoparticles impregnated into collagen-alginate scaffolds for diabetic wound healing. International Journal of Biological Macromolecules. 2016;93:1519-29. PMID: 27180291. Available from: 10.1016/j.ijbiomac.2016.05.038.

63. Wang W, Zhu R, Xie Q, Li A, Xiao Y, Li K, et al. Enhanced bioavailability and efficiency of curcumin for the treatment of asthma by its formulation in solid lipid nanoparticles. International Journal of Nanomedicine. 2012;7(7):3667-77. PMID: 22888226. Available from: $10.2147 /$ IJN.S30428.

64. Jain A, Jain SK. In vitro and cell uptake studies for targeting of ligand anchored nanoparticles for colon tumors. European Journal of Pharmaceutical Sciences. 2008;35(5):404-16. PMID: 18824095. Available from: 10.1016/j.ejps.2008.08.008.

65. Chen X, Zou LQ, Niu J, Liu W, Peng SF, Liu CM. The Stability, Sustained Release and Cellular Antioxidant Activity of Curcumin Nanoliposomes. Molecules (Basel, Switzerland). 2015;20(8):14293-311. PMID: 26251892. Available from: 10.3390/molecules200814293.

66. Zhang X, Wang R, Chen G, Dejean L, Chen QH. The Effects of Curcumin-based Compounds on Proliferation and Cell Death in Cervical Cancer Cells. Anticancer Research. 2015;35(10):5293-8. PMID: 26408689.

67. Shao P, Xuan S, Wu W, Qu L. International Journal of Biological Macromolecules Encapsulation Ef Fi Ciency and Controlled Release of Ganoderma Lucidum Polysaccharide Microcapsules by Spray Drying Using Different Combinations of Wall Materials. International Journal of Biological Macromolecules. 2019;125:962-9. PMID: 30572060. Available from: 10.1016/j.ijbiomac.2018.12.153.

68. Zhang Y, Fang M, Sun Y, Zhang T, Shi N, Li J, et al. Curcumin attenuates cerebral ischemia injury in Sprague-Dawley rats and PC12 cells by suppressing overactivated autophagy. Journal of Photochemistry and Photobiology B, Biology. 2018;184(184):1-6. PMID: 29777940. Available from: 10.1016/ j.jphotobiol.2018.05.010.

69. Khan MA, Zafaryab M, Mehdi SH, Ahmad I, Rizvi MM. Characterization and anti-proliferative activity of curcumin loaded chitosan nanoparticles in cervical cancer. International Journal of Biological Macromolecules. 2016;93:242-53. PMID: 27565296. Available from: 10.1016/j.ijbiomac.2016.08.050.

70. Gillies ER, Fréchet JM. Dendrimers and dendritic polymers in drug delivery. Drug Discovery Today. 2005;10(1):35-43. PMID: 15676297. Available from: 10.1016/S1359-6446(04)03276-3.

71. Paul DR. Elaborations on the Higuchi model for drug delivery. International Journal of Pharmaceutics. 2011;418(1):137. PMID: 21034800 . Available from: 10.1016/j.ijpharm.2010.10. 037.

72. Singhvi MSG. In-Vitro Drug Release Characterization Models. Int J Pharm Stud Res. 2011;II(I):77-84.

73. Rezaei A, Nasirpour A. Evaluation of Release Kinetics and Mechanisms of Curcumin and Curcumin- $\beta$-Cyclodextrin Inclusion Complex Incorporated in Electrospun Almond Gum/PVA Nanofibers in Simulated Saliva and Simulated Gastrointestinal Conditions. BioNanoScience. 2019;9(2):438-45. Available from: 10.1007/s12668-019-00620-4. 